NASA Technical Memorandum 105989

AIAA-93-0598

\title{
Acoustic Mode Measurements in the Inlet of a Model Turbofan Using a Continuously Rotating Rake
}

Laurence J. Heidelberg

National Aeronautics and Space Administration

Lewis Research Center

Cleveland, Ohio

and

David G. Hall

Sverdrup Technology, Inc.

Lewis Research Center Group

Brook Park, Ohio

Prepared for the

31st Aerospace Sciences Meeting

sponsored by the American Institute of Aeronautics and Astronautics

Reno, Nevada, January 11-14, 1993 


\title{
ACOUSTIC MODE MEASUREMENTS IN THE INLET OF A MODEL TURBOFAN
}

\section{USING A CONTINUOUSLY ROTATING RAKE}

\author{
Laurence J. Heidelberg \\ National Aeronautics and Space Administration \\ Lewis Research Center \\ Cleveland, Ohio 44135 \\ and \\ David G. Hall \\ Sverdrup Technology, Inc. \\ Lewis Research Center Group \\ Brook Park, Ohio 44142
}

\begin{abstract}
$\underline{\text { Abstract }}$
Comprehensive measurements of the spinning acoustic mode structure in the inlet of the Advanced Ducted Propeller (ADP) have been completed. These measurements were taken using a unique and previously untried method which was first proposed by T.G. Sofrin. A continuously rotating microphone system was employed. The ADP model was designed and built by Pratt \& Whitney and tested in the NASA Lewis 9- by 15-Ft Anechoic Wind Tunnel. Three inlet configurations were tested with cuton and cutoff stator vane sets. The cutoff stator was designed to suppress all modes at the blade passing frequency. Rotating rake measurements indicate that several extraneous circumferential modes were active. The mode orders suggest that their source was an interaction between the rotor and small interruptions in the casing tip treatment. The cuton stator produced the expected circumferential modes plus higher levels of the unexpected modes seen with the cutoff stator.
\end{abstract}

\section{Introduction}

The next generation of fan engines will likely employ a marriage of turbofan and propeller technologies to achieve significant noise and fuel consumption reductions. The Advanced Ducted Propeller (ADP) model used in this investigation was designed and built by Pratt \& Whitney, Division of United Technologies, and tested in the NASA Lewis 9- by 15-Ft Anechoic Wind Tunnel (Fig. 1). Typical of propeller technology, the ADP allows for the in-flight adjustment of the blade pitch angle. This provides reverse thrust and optimum performance over a wide range of conditions. The duct provides the noise suppression advantage of a conventional fan engine. Since future engines are expected to use still higher bypass ratios, fan noise is likely to be the dominant engine source.

One of the most important features of fan tone noise is its modal structure. Knowledge of these spinning modes helps to identify the generation mechanism, control duct propagation (thus mode knowledge is needed for acoustic treatment design) and control farfield radiation angles. Previous attempts at direct mode measurements ${ }^{1-3}$ have faced formidable practical difficulties such as: very large axial and circumferential arrays of wall microphones that are not practical for the short ducts of ultrahigh bypass engines, and radial measurements upstream of the fan that introduce a wake that interacts with the rotor thus causing extraneous modes. A continuously rotating microphone technique first proposed by T.G. Sofrin ${ }^{4}$ overcomes the problem of wake generated modes, reduces the number of microphones and duct length required. This technique has been implemented for the first time in this investigation. Two important features of this technique are: (1) each circumferential mode order generates a signal at a different frequency and (2) the interaction of the rotating rake wake with the rotor produces a signal at only one frequency, the one that corresponds to the rotor locked mode. This mode cannot propagate in a duct when the fan tip speed is subsonic (such as the ADP). A complete discription of the measurement technique and data analysis is presented in a companion paper. ${ }^{5}$

The object of the present study is to measure the modal structure in the inlet of the ADP for three inlet lengths and two stator vane blade numbers. One stator was designed to have no cuton modes at the blade passing frequency (BPF) while the other was designed for a single circumferential order. The far-field acoustic results as well as a preliminary look at some mode measurements for the ADP were reported in Ref. 6 . 
Apparatus and Procedures

Anechoic Wind Tunnel

The NASA Lewis 9- by 15-Ft Anechoic Wind Tunnel is located in the low-speed return leg of the supersonic 8- by 6-Ft Wind Tunnel. The test section Mach number was held at 0.20 , which provides a takeoff/approach test environment. The tunnel acoustic treatment provides anechoic conditions down to a frequency of $250 \mathrm{~Hz}$, which is well below the lowest BPF of the ADP model. Figure 1 shows the ADP model installed in the wind tunnel during a far-field acoustic test.

\section{Model Fan}

The ADP model featured a 16-bladed rotor $43.81 \mathrm{~cm}$ (17.25 in.) in diameter. Three inlet lengths were tested as shown in Fig. 2. The rotating rake was always installed so that the measurement plane was at the minimum diameter of the inlet (throat). The cowling was supported by the stator vanes and there were no struts or pylons crossing the fan stream. Two stator vane sets were tested. The $\mathbf{4 0}$ vane stator should have had no cuton modes at the BPF for any speed in the operating range. The 22 vane stator should have produced only the -6 circumferential order. The maximum tip speed of this fan is $275.2 \mathrm{~m} / \mathrm{s}(903 \mathrm{ft} / \mathrm{sec})$ at $12000 \mathrm{rpm}$. This corresponds to a rotor tip Mach number of 0.81 .

\section{Background-Ducted Fan Acoustic Modes}

This section presents a brief overview of the topic of ducted fan acoustic modes and fan noise generation mechanisms. A general understanding of this material is required in the discussion to follow. This topic has been the subject of an extensive body of research over the past several decades. ${ }^{7-9}$

The pressure field in a cylindrical duct containing an axial-flow fan consists of a spinning pattern with distinct maxima and minima. This pattern exhibits a characteristic, repetitive ("modal") shape. This shape can be described mathematically as a superposition of periodic functions, containing $\mathrm{m}$ periods in the circumferential direction and $\mathrm{n}$ periods in the radial direction. A rotating pressure pattern whose shape can be described using a characteristic function at one unique spatial frequency is referred to herein as a mode. Singlefrequency patterns of this type in the circumferential direction are referred to as m-modes, and in the radial direction as $\mathrm{n}$-modes.
The mechanisms which generate acoustic modes in an axial flow fan may be divided up into three classes; rotor-alone modes, rotor/stator interaction and inlet flow distortion/rotor interaction. It may be shown that the rotor-alone mechanism generates a rotor-locked circumferential mode and its harmonics. These modes have m-numbers equal to integer multiples of the number of blades, B.

The effect of rotor/stator and inlet distortion/rotor interaction is found by modifying the rotor-alone analysis to include a periodic inflow disruption with spatial order V. In the case of rotor/stator interaction, $\mathrm{V}$ is equal to the number of equally spaced stator vanes. In the case of inlet flow distortion, $\mathrm{V}$ is equal to the number of distortions, assuming equal spacing in the circumferential direction or the special harmonic content of nonuniform spacing. The m-modes generated by interaction phenomenon are given by the following $(\mathrm{k}= \pm$ any integer, $\mathrm{h}=\mathrm{BPF}$ harmonic, $1,2,3 \ldots)$ :

$$
\mathrm{m}=\mathrm{hB}-\mathrm{kV}
$$

Positive m-numbers indicate rotation in the same direction as the fan. Negative m-numbers indicate rotation in the opposite direction. The spin rate of each m-mode depends on its order (all spinning modes produce tones at the blade passing frequency and/or its harmonics):

$$
\mathrm{m} \Omega_{\mathrm{m}}=\mathrm{hB} \omega
$$

where

$\Omega_{\mathrm{m}}$ mode speed

$\omega$ fan speed

The far-field tone noise generated by an axial flow fan results from the propagation of spinning modes out of the duct. Duct propagation is studied analytically by solving the homogenous wave equation subject to boundary conditions at the duct walls. If the spin rate of a mode is sufficiently high, the sound pattern propagates in a spiral fashion down the duct and radiates to the far-field. If the pattern spin rate is low, the wave equation gives a solution where the modal amplitude decays exponentially with distance from the source. The decay rate is usually very large over a small distance, and modes with spin rates less than the critical minimum produce negligible far field noise. This minimum spin rate is referred to as "cutoff." Various simple formulas exist to predict the occurrence of cutoff. The following general rules may be stated: 
(1) As fan speed increases, so does the circumferential Mach number at the wall. This allows more and more modes to cut on and begin propagating. This is seen in far-field noise levels, which increase with higher fan speeds.

(2) For a given fan speed, a larger duct throat diameter will allow more modes to propagate.

(3) As fan speed increases, modes with low m- and $\mathrm{n}$-orders cut on first.

(4) The rotor locked mode (order $\mathrm{m}=\mathrm{B}$ ), and all modes of greater order, can only propagate for blade tip mach numbers above 1.0.

To summarize, the occurrence of a given mode in the duct depends on the mode generation mechanisms (rotor alone, rotor/disturbance interaction and rotor/ stator interaction). The propagation of a mode to the far field depends primarily on duct geometry and fan speed.

\section{$\underline{\text { Rotating Rake }}$}

Figure $3(\mathrm{a})$ is a photo of the rotating rake installed on the inlet of the ADP model. The rake is attached to a ring gear surrounding the inlet. This gear rotates at exactly $1 / 250$ of the fan speed and is phase locked to the fan. A control system using a stepping motor drives the ring gear and rake. This control system can be described as an electronic gear box. The angular relationship between the fan and the rake is in general held to within $\pm 0.2^{\circ}$ of the ideal. Five miniature pressure transducers are mounted on the rake (Fig. $3(\mathrm{~b})$ ). The pressure signals are transmitted across the rotating boundary by telemetry. By running the rake at two different radial positions, measurements at nine different radii were obtained, along with one repeat radial location. The design, installation, and operation of the rake and control system are described in Ref. 10 .

The rotating frame of reference provided by the rake separates each circumferential mode order, m, into a different frequency by Doppler shift. This happens because each $\mathrm{m}$ order spins at a different rate which is inversely proportional to its order. For $\mathrm{m}=\mathrm{B}$, where $\mathrm{B}$ is the rotor blade number, the mode rotates at the same speed as the rotor. This mode is referred to as the rotor locked mode. On the rotating frame of reference the rake wake-rotor interaction is seen at the same frequency as the rotor locked mode. Thus, the rake wake-rotor interaction only contaminates one potential mode measurement. This mode only appears when the rotor tip speed is above the speed of sound, which is not the case in the ADP model.
The data for each radial position is fan synchronously digitized. A very narrow band complex spectrum is obtained by time domain ensemble averaging synchronous to the rake. This spectrum contains a cluster of tones centered on the BPF and its harmonics. Each tone that corresponds to an $\mathrm{m}$ order, the phase and magnitude at each radius is used to calculate the radial order. A least squares curve fit using Bessel functions is employed for this calculation. A more complete description of the data collection and analysis is presented in a companion paper. ${ }^{5}$

\section{$\underline{\text { Results and Discussion }}$}

The long and medium length inlets were tested with both the 40 and 22 vane stators while the short inlet was tested with the 22 vane stator only. All the test data were obtained with the short spinner and nozzle, takeoff blade setting angle ( $11^{\circ}$ less than cruise) and the axial skewed grooved rub strip. Mode measurements were made for four different rotor tip Mach numbers, $\mathrm{M}_{\mathrm{t}}, 0.65,0.73,0.77$, and 0.81 corresponding to the following corrected rotor speeds: 9600, 10800,11400 , and $12000 \mathrm{rpm}$. Both the BPF and 2-BPF modal structures will be presented. Although the spectral data was available for the 3-BPF modes, there were an insufficient number of radial measurement locations available to resolve the highest order radial modes present at this frequency.

\section{Spectral Data}

The effect of rotation on the rake signal can be seen in Fig. 4. These spectra were obtained using an on-line signal analyzer during testing. They have a very narrow resolution bandwidth ( 0.0005 shaft orders) and are a result of fan synchronous digitizing. When the rake is stationary all of the modes of the BPF appear at one frequency (16.000 shaft orders). When the rake rotates, a Doppler shift occurs that splits the BPF tone into many different frequencies, each representing a different spin rate, and thus circumferential order. It should be noted that the tone corresponding to $\mathrm{m}=\mathbf{1 6}$ is spurious and a result of the rake wake interaction with the rotor. The separation between $\mathrm{m}$ orders in terms of shaft orders is equal to the rake-fan speed ratio. In this case, the $\mathrm{m}$ orders are $1 / 250$ or 0.004 shaft orders apart.

As illustrated above the circumferential modal decomposition was obtained from a very narrow band spectral analysis. This analysis used fan rotor synchronous digitizing and time domain rake synchronous ensemble averaging to produce a magnitude and phase for each $m$ order at each radial location. Next, a radial mode analysis was performed using the radial 
distribution data for each $\mathrm{m}$ order as the input to a least squares curve fitting program. Bessel eigenfunctions were used in calculating the radial coefficients. A complete description of this process can be found in Ref. 5 .

\section{Modal Data}

When all significant $\mathrm{m}$ orders are resolved into their radial components, a complete modal picture can be seen in the form of a three-dimensional bar graph as in Fig. 5(a). The mode amplitudes in Pascals are plotted against both circumferential, $\mathrm{m}$ and radial, $\mathrm{n}$ orders. The case plotted here is for the 22 vane (cuton) stator and the long inlet at BPF and a rotor tip Mach number of 0.77. Before a discussion of the modal plot begins it would be helpful to normalize the amplitudes. The large amplitudes seen at the higher $m$ and $n$ orders (cutoff ratio near unity) are misleading when it comes to evaluating their contribution to far-field noise or total power. The modes $(10,0),(11,0)$, and $(12,0)$ are typical near-cutoff modes with high levels and little or no acoustic power. These near cutoff modes are propagating at high angles to the duct axis and therefore contribute much less to the overall noise signature for a given mode amplitude compared to modes propagating at angles close to the axis. To compensate for this effect, the amplitudes of all modes were normalized by multiplying them by the cosine of their respective propagation angles. The normalized amplitude represents the component of the amplitude in the axial direction. Figures 5(a) and (b) can be compared to see the effect of this normalization. The largest differences occur at the higher values of $\mathrm{m}$ and $\mathrm{n}$. Note that modes $(11,0)$ and $(12,0)$ do not appear in the normalized plot since they are cutoff. The $(10,0)$ mode is cuton but has a greatly reduced amplitude. All the remaining modal data in this paper will be presented using the normalized amplitudes.

One limitation of the mode measurements in this investigation is that, with only one axial rake location, the axial direction of travel for any mode is not certain. A mode could, in some cases be traveling towards instead of away from the fan. Since the net acoustic power is traveling away from the fan it might be reasonable to assume that most of the modes are doing likewise. It should be kept in mind that any strong reflections near the end of the fan duct could lead to erroneous interpretation of results for a particular mode.

BPF Modal Structure.-Figures 6 to 9 show a comparison of the BPF modal structure of the 22 and 40 vane stator sets, for both the long and medium inlets. Since the short inlet was only run with the 22 vanes it will be shown separately. Figure 6 shows the effect of a cuton stator set ( 22 vanes) for both inlets at a low rotor speed, $\mathbf{M}_{\mathrm{t}}=0.65$. The expected circumferential order of
$\mathbf{M}=-6$ is very obvious. This $\mathrm{m}$ order is a result of the interaction of the 16 blade wakes with the 22 vanes.

For the 40 vane stator no modes should be cuton at the BPF. As seen in Fig. 6 there are many modes present for the 40 vane stators. These extraneous modes also show up in the 22 vane cases. A closer examination of the extraneous modes, especially at the higher speeds shown in Figs. 7 to 9 reveal a pattern of four difference in $\mathrm{m}$ order. This $\Delta \mathrm{m}=4$ pattern, and Eq. (1), suggest the interaction of the rotor with a fixed four lobed distortion pattern in the inlet. No obvious cause for such an inlet distortion pattern could be found. Farfield tone directivity patterns ${ }^{5}$ also suggest the presence of extraneous modes. It is not unusual to see residual tones in fans with cutoff stators, though the tones seen in this investigation may be unusually strong.

A careful examination of the fan casing tip treatment used for these tests revealed two possible sources for extraneous modes. The casing treatment and rub strip consists of two rows of axial slots skewed relative to the radius. The treatment was fabricated in eight circumferential segments. At each location where the segments join there was a small area with no slots. This symmetrical interruption of the treatment could lead to a periodic loading change at the blade tip and thus extraneous modes of $\Delta \mathrm{m}=8$ centered on $\mathrm{m}=8$. In addition to these eight segments, four blade tip clearance probes were installed through the treatment, $90^{\circ}$ apart around the casing, in the center of every other segment. This could lead to a periodic blade loading change of four per revolution as well as $\mathbf{1 6}$ (the distance between the probe and either end of the segment is $1 / 16$ of the circumference). These periodic loading changes lead to modes of $\Delta \mathrm{m}=4$ centered on $\mathrm{m}=12$ and $\Delta \mathrm{m}=16$ centered on $\mathrm{m}=0$. The $\mathrm{m}=0$ mode is often the largest in the BPF data. The $m= \pm 16$ modes for the 2-BPF data will later be shown to be very strong.

Figure 7 shows the modal structure for $M_{t}=0.73$. For the 22 vane case, the $\mathrm{m}=-6$ order is much larger then the previous speed. Also, the higher speed is responsible for the mode $(-6,1)$ to just start to be cuton. Not only can the effect of rotor speed on cuton be seen but, the inlet can also effect mode cuton. The medium inlet has a slightly larger throat diameter then the long inlet. This allows a mode to be cuton first in the medium inlet as can be seen by the presence of the $(10,0)$ mode in Fig. 7(b). At still higher speed, $M_{t}=0.77$, still more modes appear as shown in Fig. 8. Higher speed allows higher radial orders, $\mathbf{n}$ to be cuton as well, as can be seen for the long inlet where $n=3$ appears for $\mathrm{m}=0$. Only the long inlet has the $\mathrm{n}=3$ mode because it has a higher hub-tip ratio which allows this mode to propagate. The $\Delta \mathrm{m}=4$ pattern is more obvious at 
this speed. The importance of the $\mathrm{m}=0$ mode seems to be growing, particularly for the long inlet. For this inlet, the $(0,1)$ mode is the largest, even for the "cuton" 22 vane stators.

It should be noted here that, the importance of an individual mode cannot always be determined where more then one radial order is present. The far-field radiation pattern is greatly effected by the phasing of the individual radial orders. Also note that the amplitude scale used on the plots is linear, thus tending to exaggerate differences between configurations.

Figure 9 shows the modal structure for the highest speed, $\mathbf{M}_{\mathbf{t}}=0.81$. The results here are similar to the previous speed, with the exception of a few more modes being cuton. The $\mathrm{m}= \pm \mathbf{1 2}$ orders are now cuton for the medium inlet.

The medium inlet appears to be quieter based on the trends shown in Figs. 6 to 9. The far-field measurement do not generally show this, but the far-field trends depend on speed and whether sideline or polar directivity comparisons are made.

Another trend in the modal data is that the $\Delta \mathrm{m}=4$ modes are higher for the 22 vane (cuton) stators. It is not known what is responsible for these increased levels.

In another investigation, as yet unpublished, the complex mode amplitudes for some of the configuration just presented were used as input to a finite element farfield radiation code. Both 40 and 22 vane, as well as long and medium inlet cases were run and yielded good agreement with the far-field measurements. These results add confidence to both the mode measurements and the code.

The modal structure for the short inlet, 22 vane configuration is shown in Fig. 10 for all four speeds. When these levels are compared to the medium inlet with 22 vanes in Figs. 6 to 9, they are generally lower. Far-field results ${ }^{6}$ show little or no difference. Due to the very short length (length to fan diameter ratio of 0.21 ) the measuring plane is extremely close to the fan, less then a wavelength. There may be a near-field effect that in some way is responsible for the lower levels. One expected near-field effect is higher levels of cutoff modes. This effect was not observed in the data; perhaps because, at decay rates of the order of $200 \mathrm{~dB}$ per $\mathrm{L} / \mathrm{D}$, the measurement was not close enough to the fan to observe these cutoff modes.

2-BBF Modal Structure.-Figures 11 to 14 show a comparison of the $2-\mathrm{BPF}$ modal structures for the 22 and 40 vane stator configurations for both the long and medium inlets. Not only are there twice as many $m$ orders cuton for this harmonic, but twice as many $n$ orders are cuton as well. There are seven $n$ orders (0 to 6$)$ cuton in some cases. This presents a problem, in that the least squares Bessel function solution for radial mode decomposition can become less suitable and accurate with data for only nine radial locations available. The quality of some of the 2-BPF solutions for high $n$ orders is less reliable than the rest of the modal data presented.

Both the 22 and 40 vane stators have cuton rotorstator interaction modes for 2 BPF. From Eq. (1) the 22 vane configuration produce two $\mathrm{m}$ orders, $\mathrm{m}=10$, -12 , while the 40 vane configuration produce only one, $\mathrm{m}=-8$. The $\mathrm{m}=10$ for the 22 vane configuration can be seen in Fig. 11 where the lowest speed data, $\mathrm{M}_{\mathrm{t}}=0.65$ is shown. Only the medium inlet data for the 22 vane configuration is available here. This data shows three radial modes for $\mathrm{m}=10$, all over $100 \mathrm{~Pa}$. The other expected $\mathrm{m}$ order, $\mathrm{m}=-12$ also happens to be one of the extraneous modes $(\Delta \mathrm{m}=4)$, and so the level due to the rotor-stator interaction is uncertain. In any case, it has a low amplitude, and this counterrotating (negative $\mathrm{m}$ orders rotate opposite the direction of the rotor) is not a significant contributor to the overall noise. The expected mode for the 40 vanes is also counterrotating, $\mathrm{m}=-8$, and again it has a relatively low level, which may not completely be due to rotorstator interaction. Low levels of counterrotating modes may be a result of these modes being reflected from the rotor blades as they try to propagate upstream through the rotor. ${ }^{11}$ Unfortunately, it is expected that the energy these modes carry would be transferred to the aft duct. The addition of aft mode measurements for this fan could prove valuable in understanding the rotorstator reflection and transmission problem.

At the higher speeds (Figs. 12 to 14 ) the overall modal structure for both vane sets remained similar to the lowest speed except for some drop in levels at the highest speed, $M_{t}=0.81$. The $\Delta \mathrm{m}=4$ pattern is very evident at most speeds and for both inlets. Just as in the $\mathrm{BPF}$ data, the $2-\mathrm{BPF}$ data for 22 vanes have higher levels of the extraneous modes particularly near and above the large rotor-stator mode of $\mathrm{m}=10$. For the 40 vane stators, the dominant modes are the extraneous modes $(\Delta m=4)$ even though there is a cuton rotorstator mode. A pattern of $\Delta \mathrm{m}=8$ can be seen in much of the 40 vane data. The $\mathrm{m}=16,0$, and -16 orders are usually some of the most prominent. This is further evidence that the extraneous modes might be a result of the casing tip treatment interruptions of $1 / 4$, $1 / 8$, and $1 / 16$ of the circumference.

In most cases, the differences between the long and medium inlet were small. For the short inlet, only 
radial mode solutions for one speed, $\mathrm{M}_{\mathrm{t}}=0.81$ could be obtained. Much of the spectral data for the short inlet had phase shifts between the two rake immersions. With only five radial positions available for a single rake immersion (consistent phase angle data), there is insufficient input for a solution for the seven radial orders required for low $\mathrm{m}$ orders. Since only the modal structure for the short inlet with 22 vanes is available at $\mathrm{M}_{\mathrm{t}}=0.81$, Fig. 15 shows a comparison of all the inlets for this speed and vane number. Although the levels may be somewhat lower for the short inlet, this may not be significant, especially for the expected $\mathrm{m}=10$ modes which are the highest. When all the normalized amplitudes of the radial modes are summed for $\mathrm{m}=10$, the largest difference between inlets is less then 20 percent, which is small in terms of decibels. The extraneous modes particularly at $\mathrm{m}= \pm 16,0$, and 20 can be fairly strong.

\section{$\underline{\text { Concluding Remarks }}$}

This paper presented the acoustic modal structure in the inlet of the ADP turbofan model as measured by a unique and previously untried method. The BPF and 2-BPF modal structure for five configurations involving the inlet length and stator vane number were measured in the NASA Lewis 9 - by $15-\mathrm{Ft}$ Wind Tunnel. The continuously rotating rake technique employed here was able to measure both circumferential and radial mode order with no apparent interference with the noise sources.

The modal structure for configuration with a cuton stator exhibited high levels of the expected $\mathrm{m}$ order. A complicated and unexpected modal structure was observed in addition to the expected one. These extraneous modes were present with both cuton and cutoff stators. The extraneous modes had a pattern of $\Delta \mathrm{m}=4,8$, and 16 , which was found to be the same as a pattern of symmetrical interruptions of the fan casing tip treatment. It seems that these small interruptions in the treatment may have caused periodic loading changes at the blade tip which result in extraneous modes. Further evidence is needed to confirm this rotor-casing treatment interaction source. Higher levels of the extraneous modes were observed when the rotor-stator interaction was cuton.

Some indication of modal reflection from the rotor for counterrotating modes coming from the stator was observed. This should be further investigated by measuring the modes in the aft fan duct as well as far-field acoustics.

Much of the expected behavior of the circumferential and radial mode orders with speed was observed. The effect of inlet length was difficult to estimate.
There was some tendency for the mode levels to drop with length. This was most evident in the short inlet at BPF.

Since mode measurements were made in only one axial location, the direction of travel of a mode is not certain. It is generally assumed that most modes are traveling away from the source. Duct termination reflections could confuse the interpretation of the data. Additionally, the presence of many radial orders makes it difficult to project modal changes to far-field changes. These limitations restrict the interpretation of modal data. There are many tools that could prove useful to overcome these limitations. One is a duct to far-field radiation code. Preliminary and as yet unpublished results from such a code indicate good agreement with far-field data, when mode data from this investigation was used as input.

\section{References}

1. Pickett, G.F., Sofrin, T.G., and Wells, R.A., "Method of Fan Sound Mode Structure Determination. Final Report," NASA CR-135293, Aug. 1977.

2. Moore, C.J., "Measurement of Radial and Circumferential Modes in Annular and Circular Fan Ducts," Journal of Sound and Vibration, Vol. 62, No. 2, 1979, pp. 235-256.

3. Joppa, P.D., "An Acoustic Mode Measurement Technique," AIAA Paper 84-2337, Oct. 1984.

4. Cicon, D.E., Sofrin, T.G., and Mathews, D.C., "Investigation of Continuously Traversing Microphone System for Mode Measurement," NASA CR-168040, Nov. 1982.

5. Hall, D.G., Heidelberg, L.J., and Konno, K., "Acoustic Mode Measurements in the Inlet of a Model Turbofan Using a Continuously Rotating Rake: Data Collection/Anlaysis Techniques," NASA TM-105936, Jan. 1993 (Also, AIAA Paper 93-0599, Jan. 1993).

6. Woodward, R.P., Bock, L.A., Heidelberg, L.J., and Hall, D.G., "Far-Field Noise and Internal Modes From a Ducted Propeller at Simulated Aircraft Takeoff Conditions." AIAA Paper 92-0371, Jan. 1992 (Also, NASA TM-105369, 1992).

7. Tyler, J.M., and Sofrin, T.G., "Axial Flow Compressor Studies," SAE Transactions, Vol. 70, 1962, pp. 309-332. 
8. Sofrin, T.G., "Some Modal-Frequency Spectra of Fan Noise," AIAA Paper 81-1990, Oct. 1981.

9. Rice, E.J., Heidman, M.F., and Sofrin, T.G., "Modal Propagation Angles in a Cylindrical Duct with Flow and Their Relation to Sound Radiation," AIAA Paper 79-0183, Jan. 1979 (Also, NASA TM-79030, Jan. 1979).

10. Konno, K.E., and Hausmann, C.R., "Rotating Rake Design for Unique Measurement of Fan-Generated
Spinning Acoustic Modes," To be published as NASA TM-105946, 1993.

11. Topol, D.A., Holhubner, S.C., and Mathews, D.C., "A Reflection Mechanism for Aft Fan Tone Noise from Turbofan Engines," AIAA Paper 87-2699, Oct. 1987.

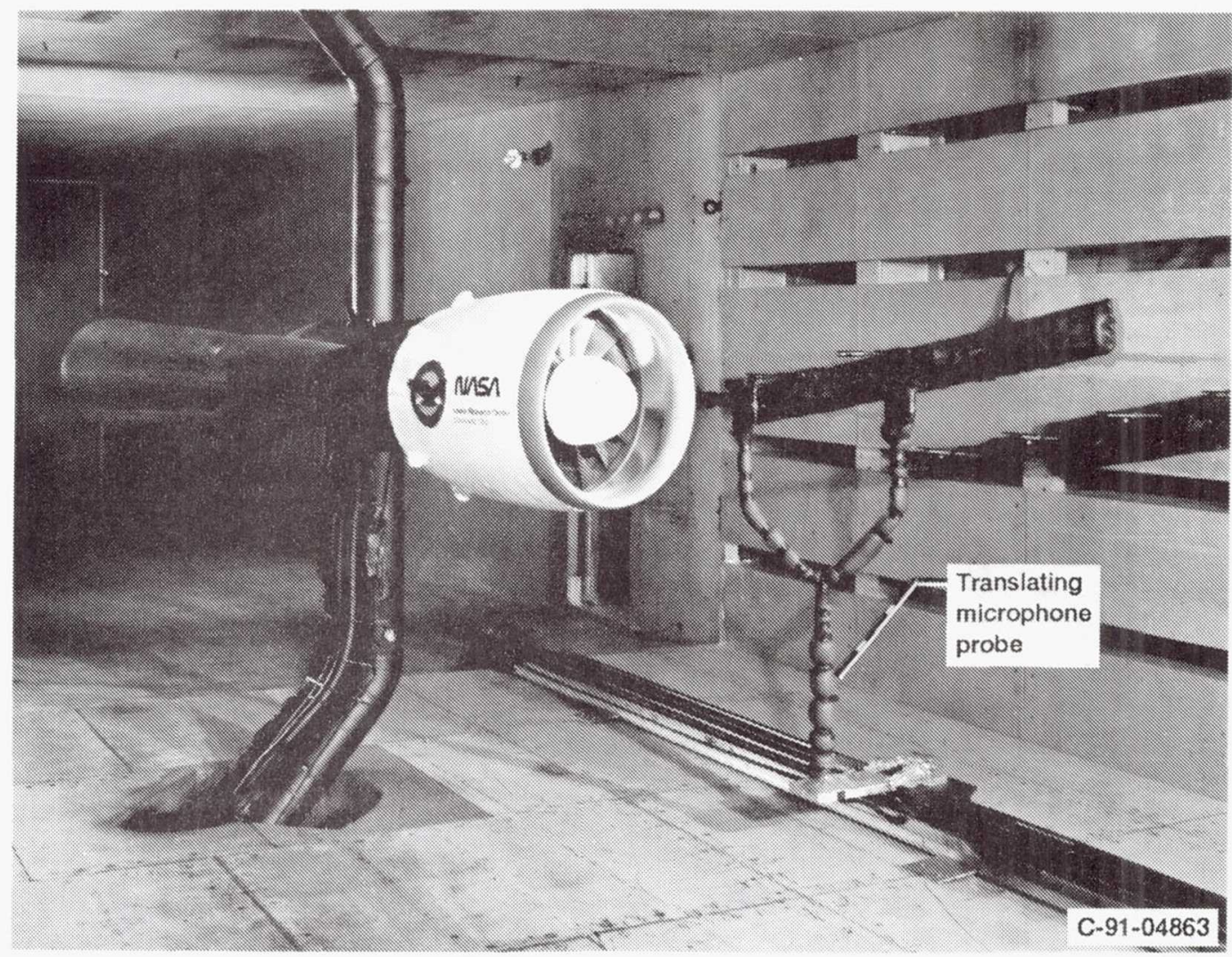

Figure 1.-Photograph of the advanced ducted propeller model installed in the $9 \times 5 \mathrm{ft}$ anechoic wind tunnel. 


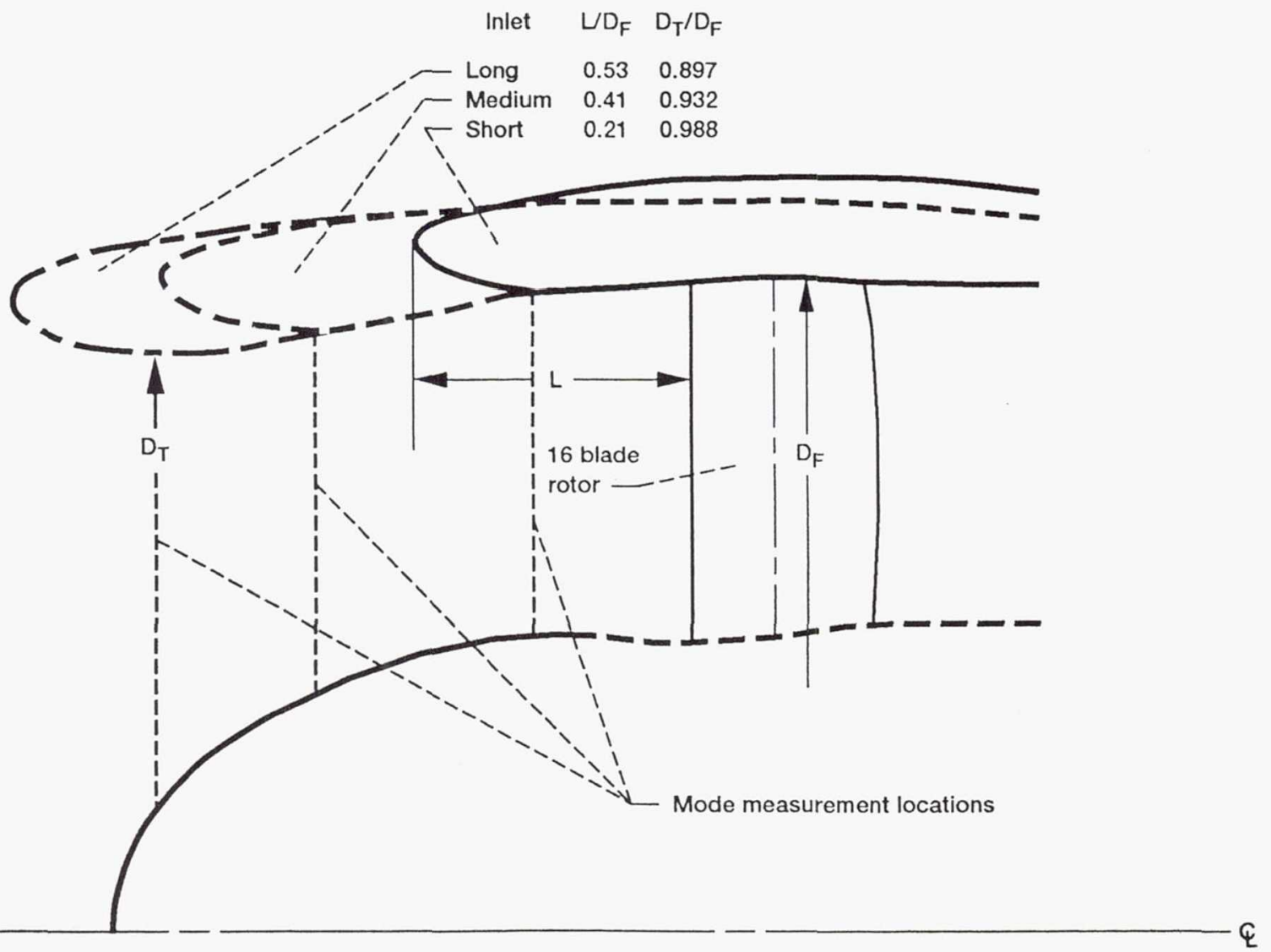

Figure 2.-ADP inlet configurations. 


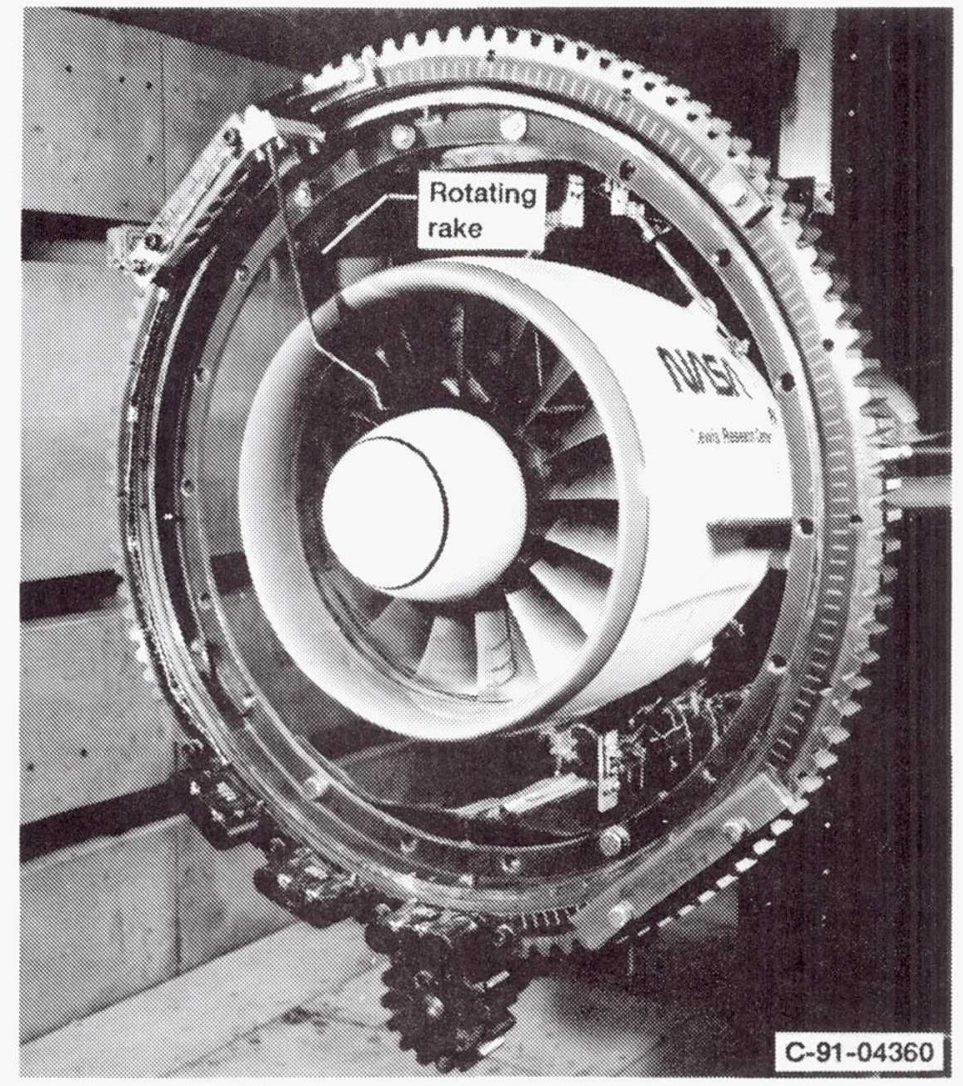

(a) Photograph of installation.
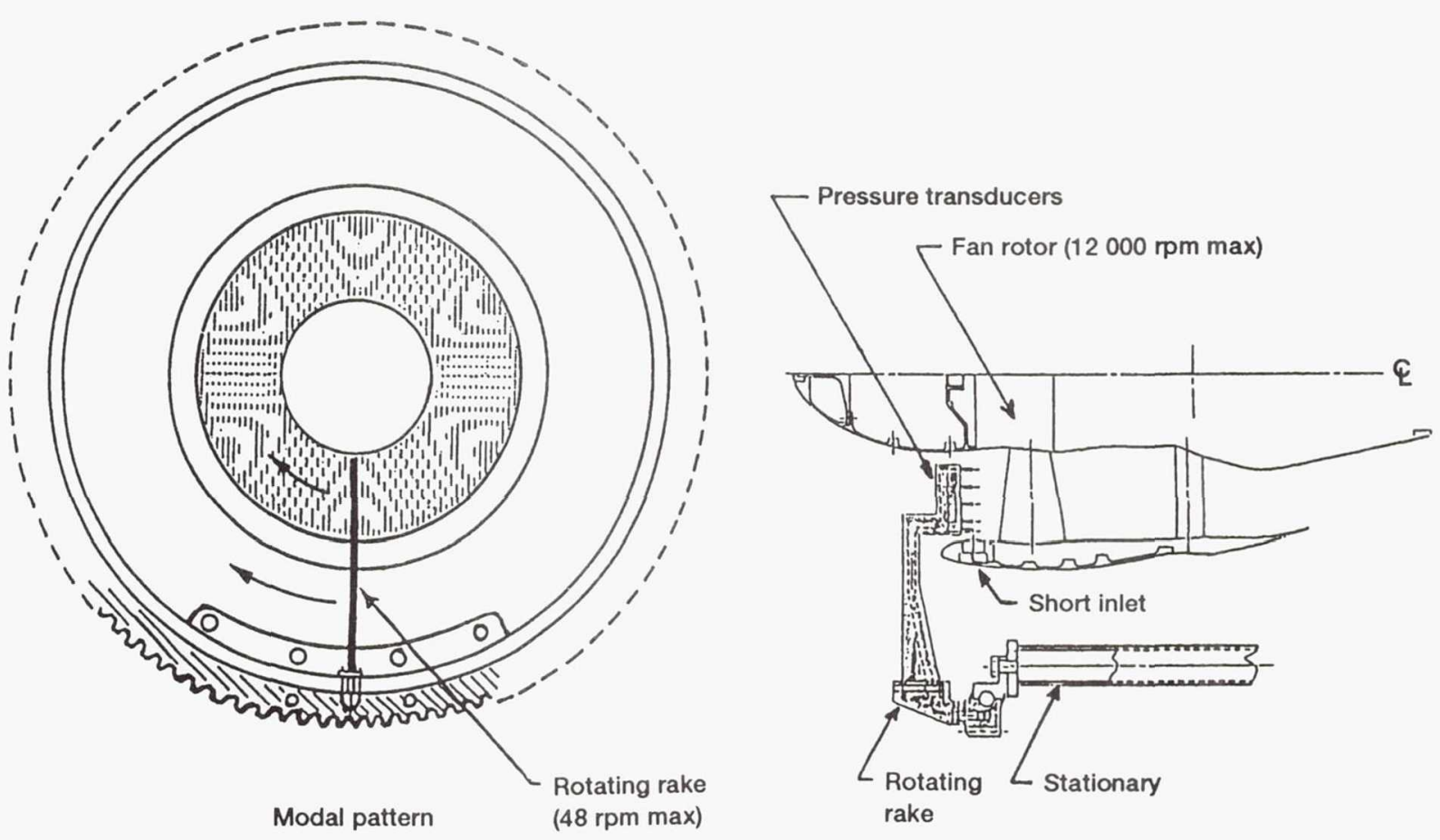

(b) Details of rotating rake installation.

Figure 3.-Rotating rake installed on the inlet of the ADP model. 


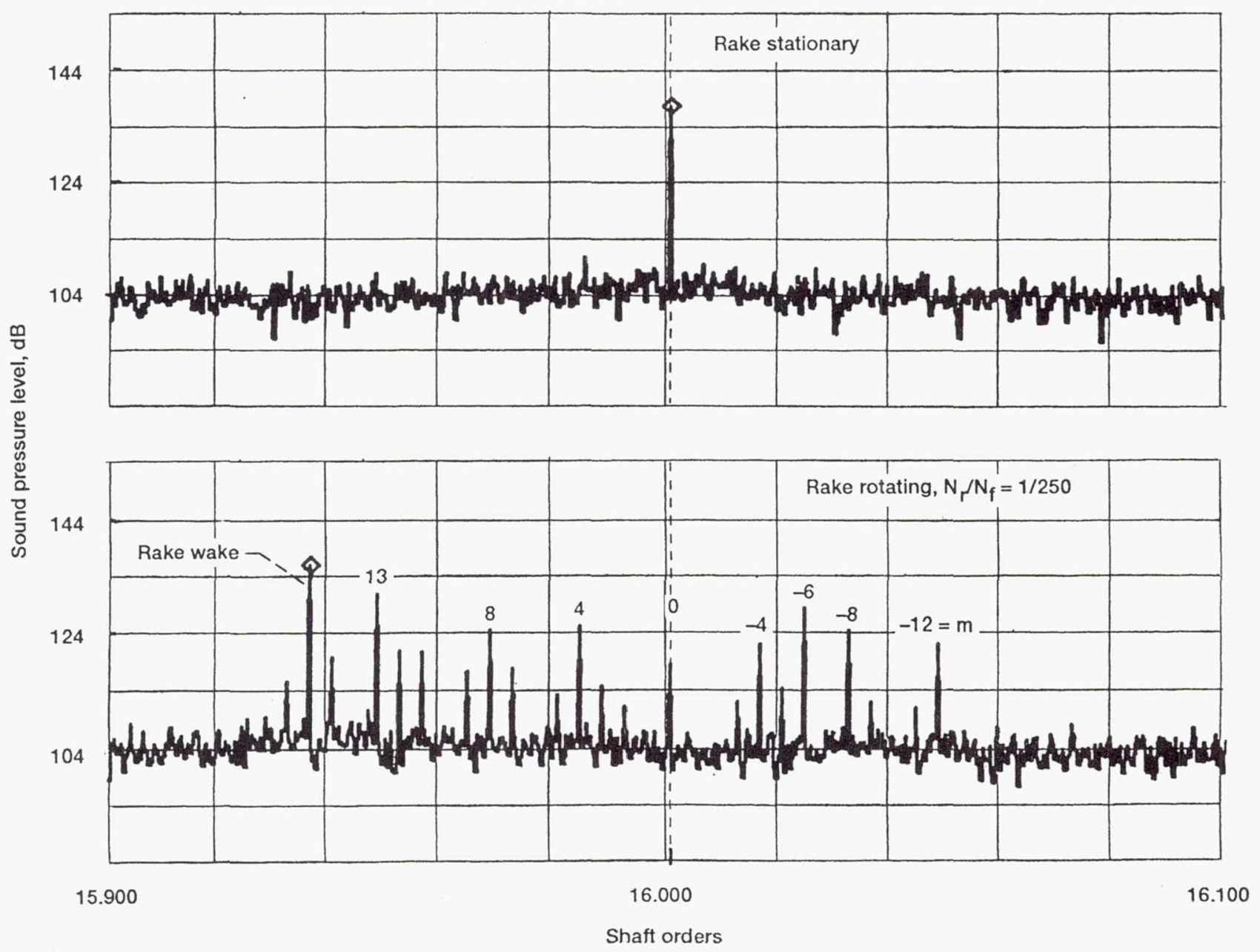

Figure 4.-Effect of rake rotation on spectrum. Long inlet, 22 vanes, $M_{t}=0.81,2.3 \mathrm{~cm}(0.91 \mathrm{in}$.) from wall. 


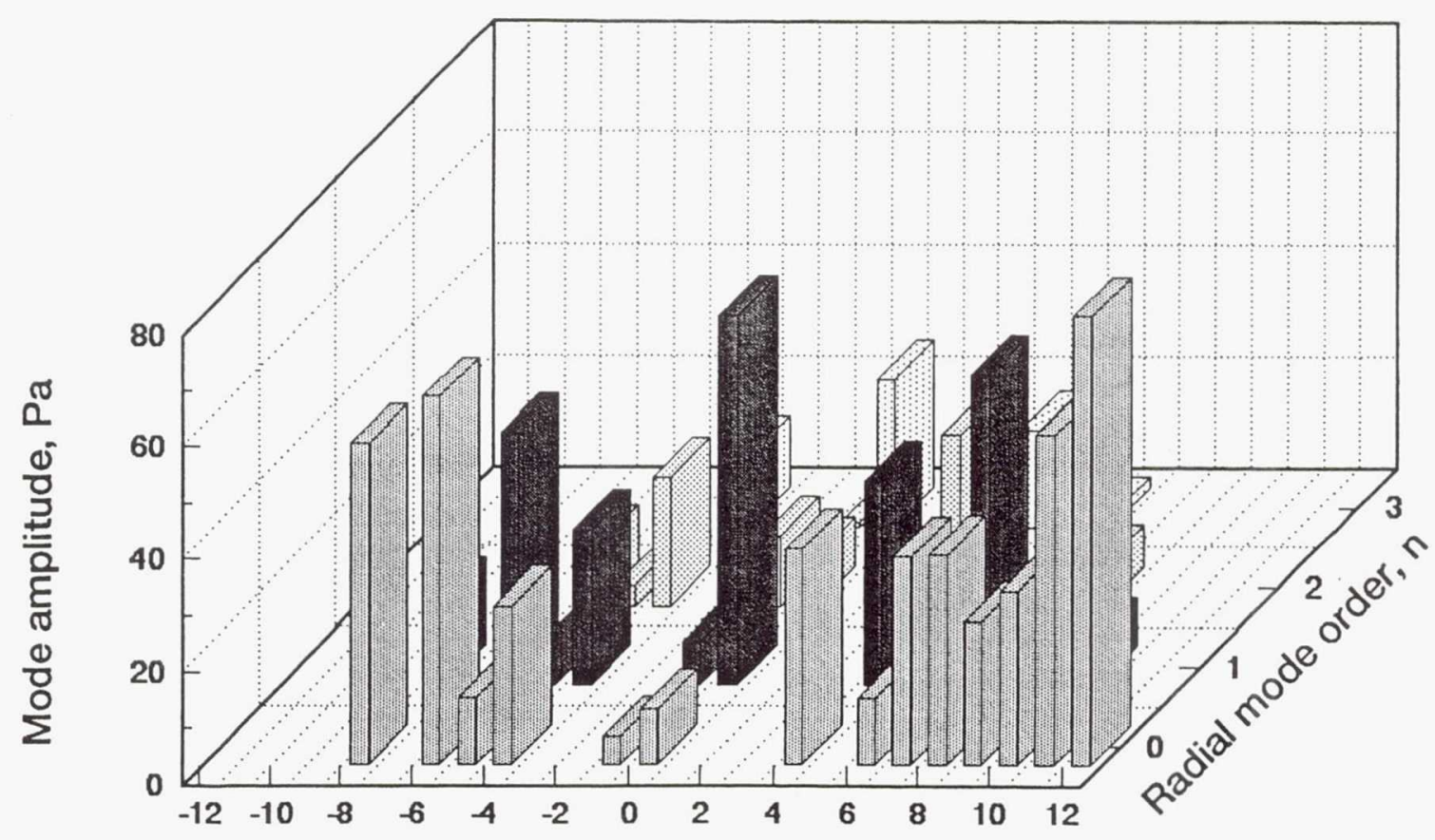

(a) As measured.

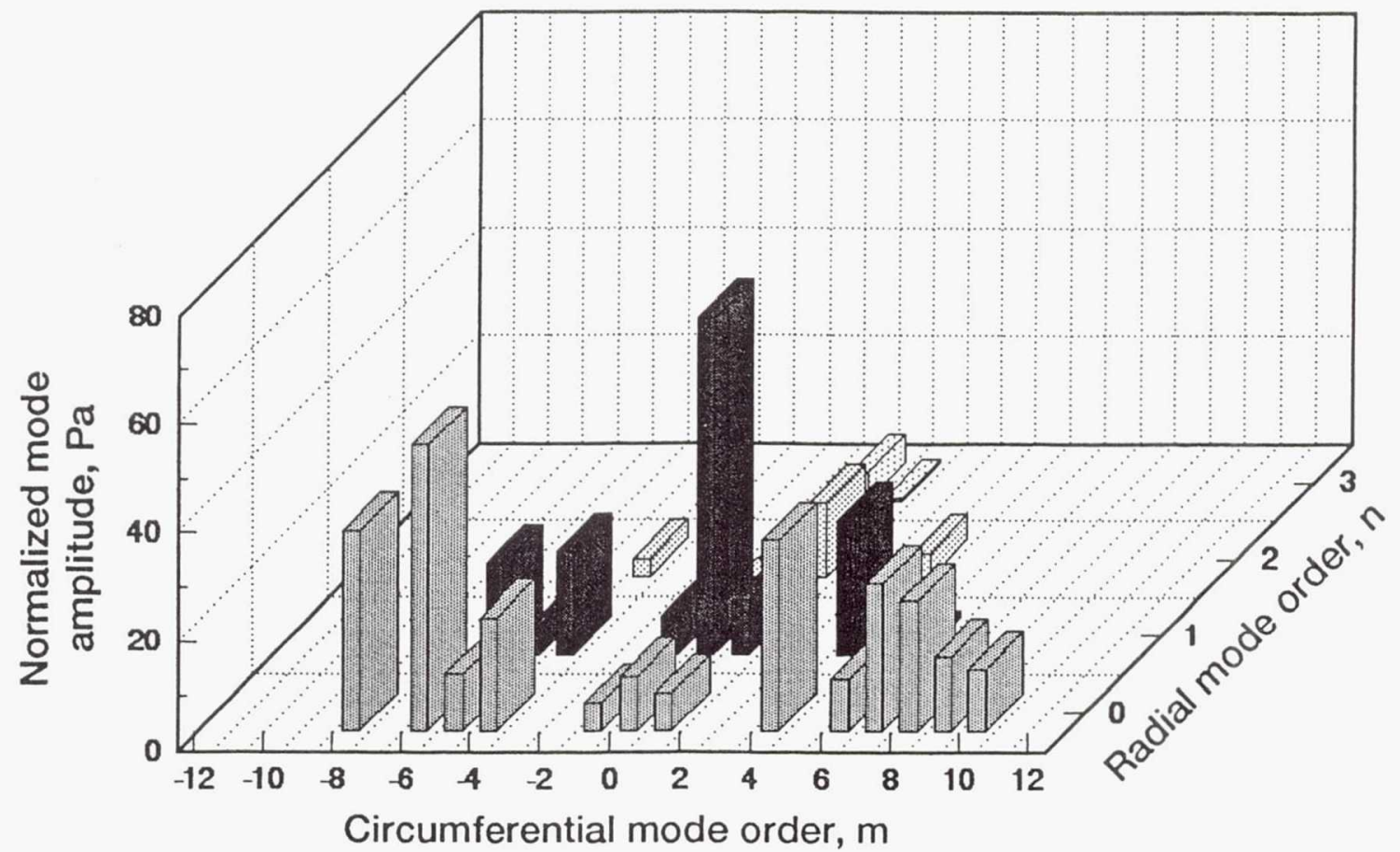

(b) Normalized.

Figure 5.-Effect of normalization on BPF mode amplitudes, long inlet, 22 vanes, $M_{t}=0.77$. 


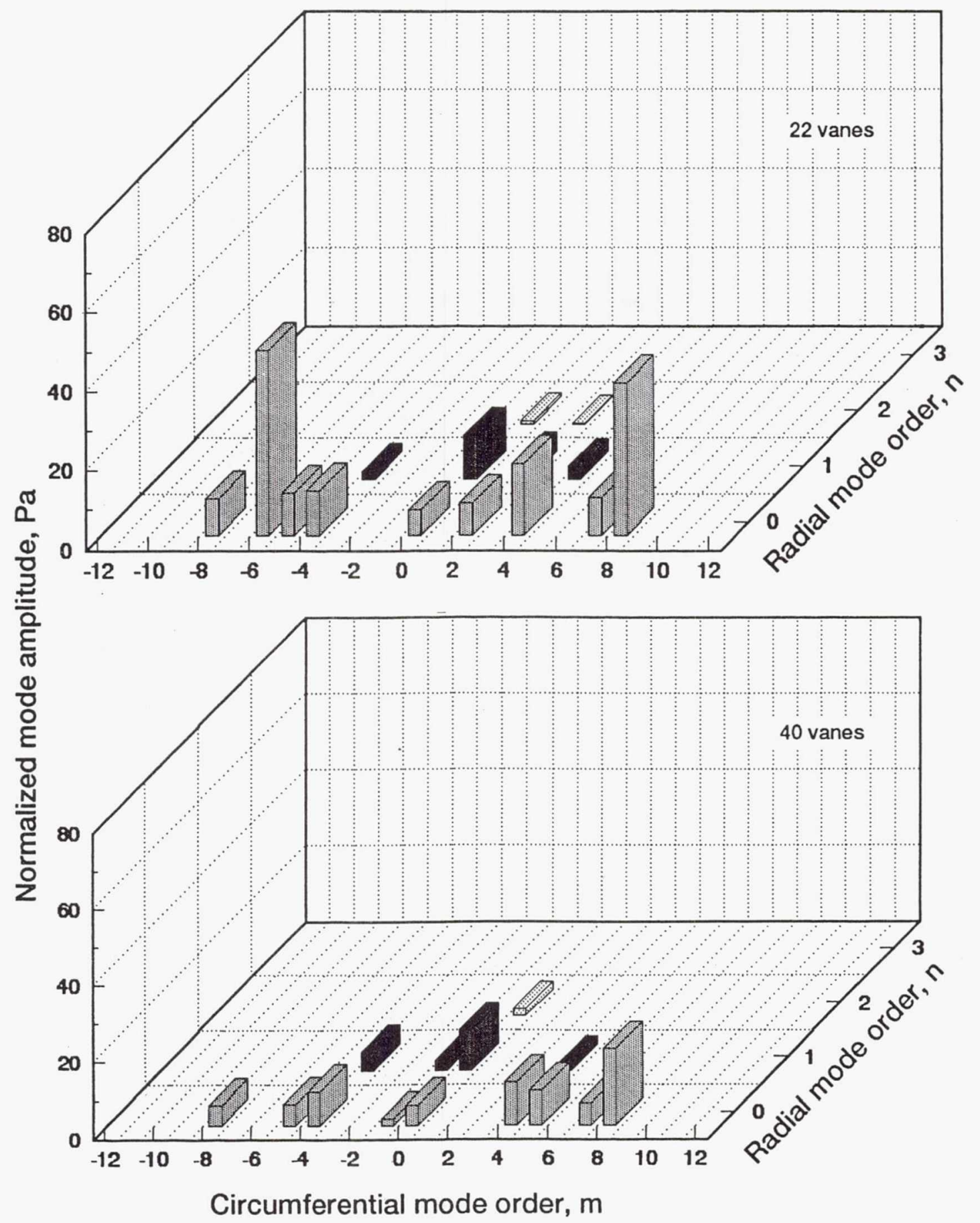

(a) Long inlet.

Figure 6. $-\mathrm{BPF}$ modal structure at $\mathrm{M}_{\mathrm{t}}=0.65$. 


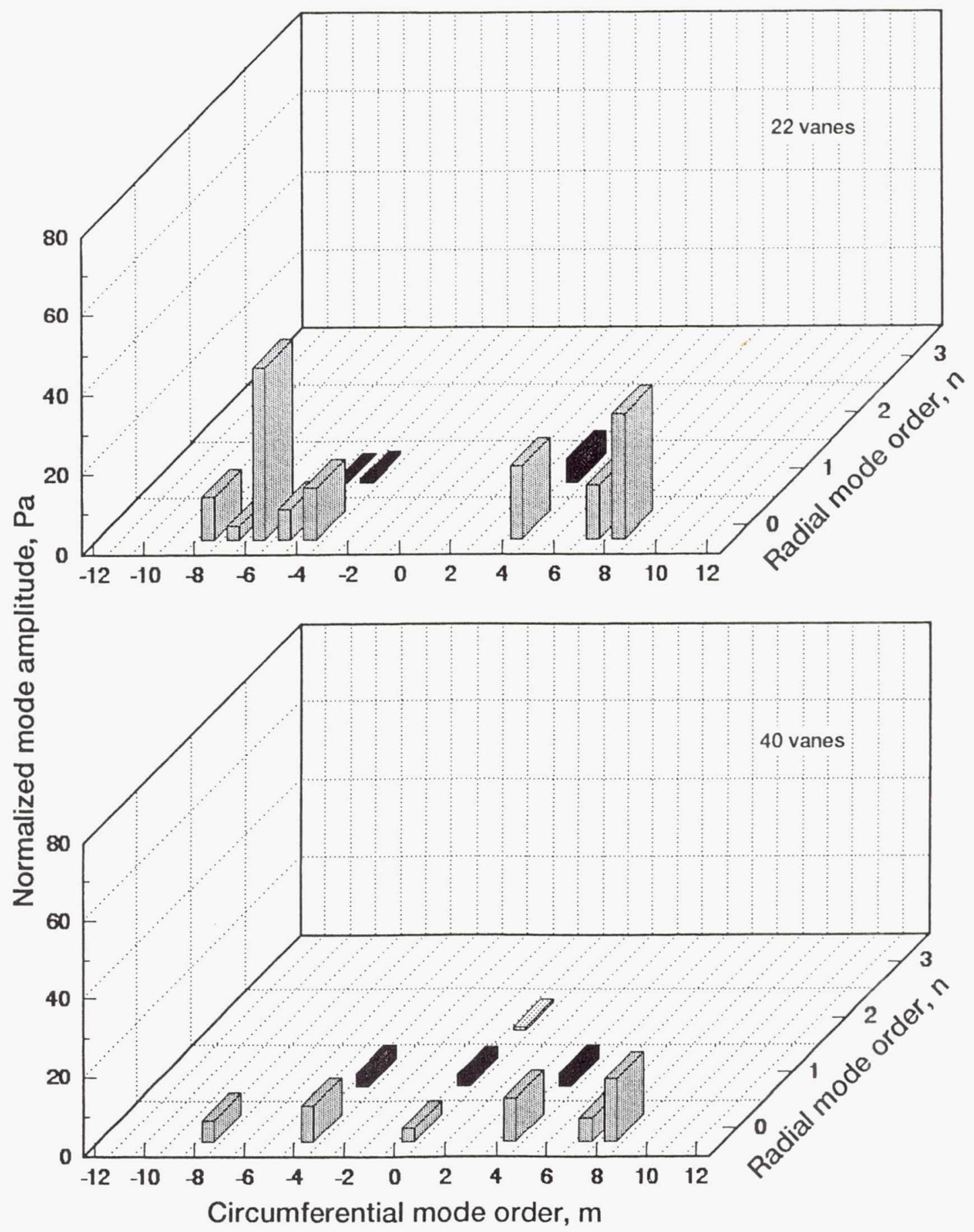

(b) Medium inlet.

Figure 6.-Concluded. 


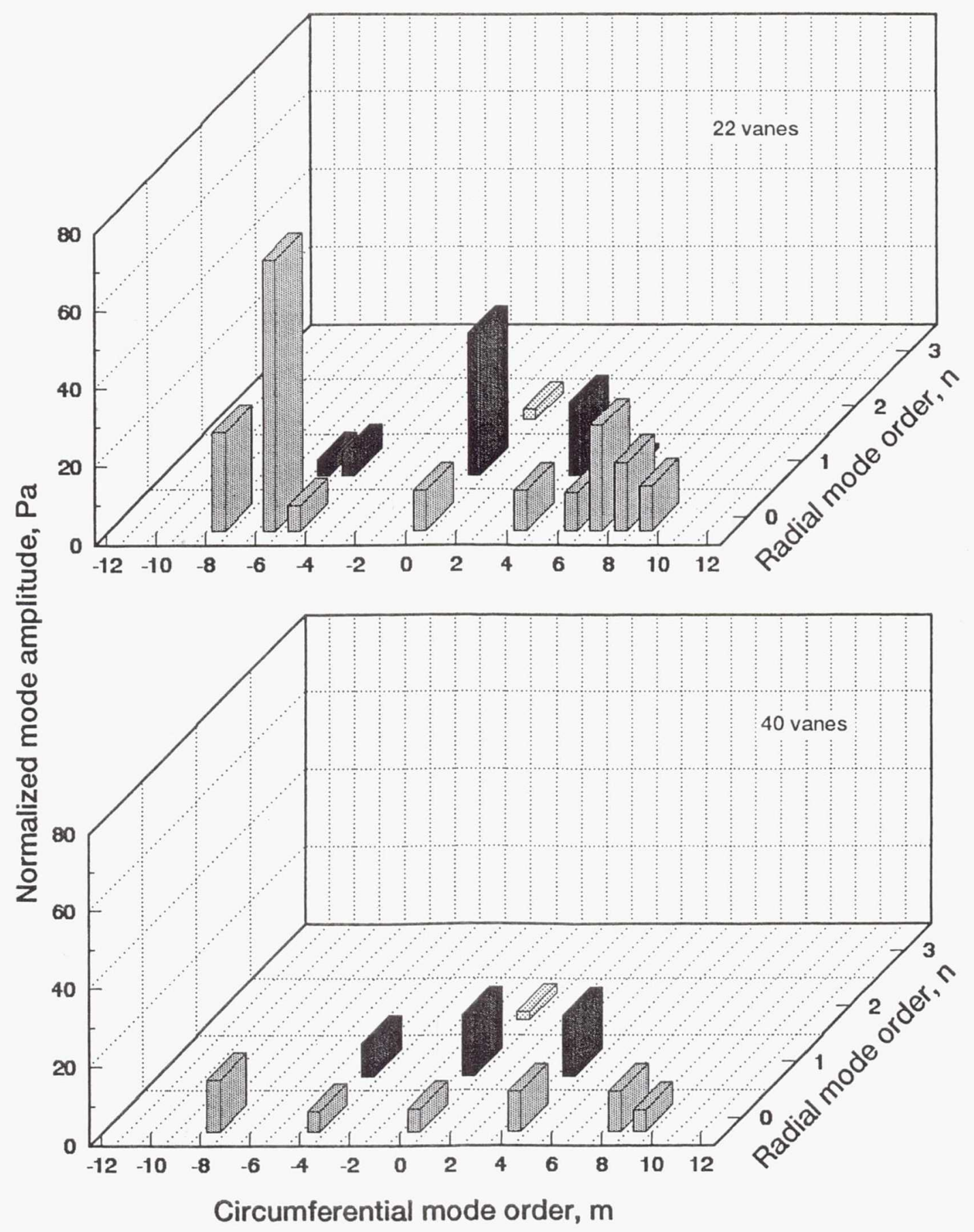

(a) Long inlet.

Figure 7.-BPF modal structure at $\mathrm{M}_{\mathrm{t}}=0.73$. 


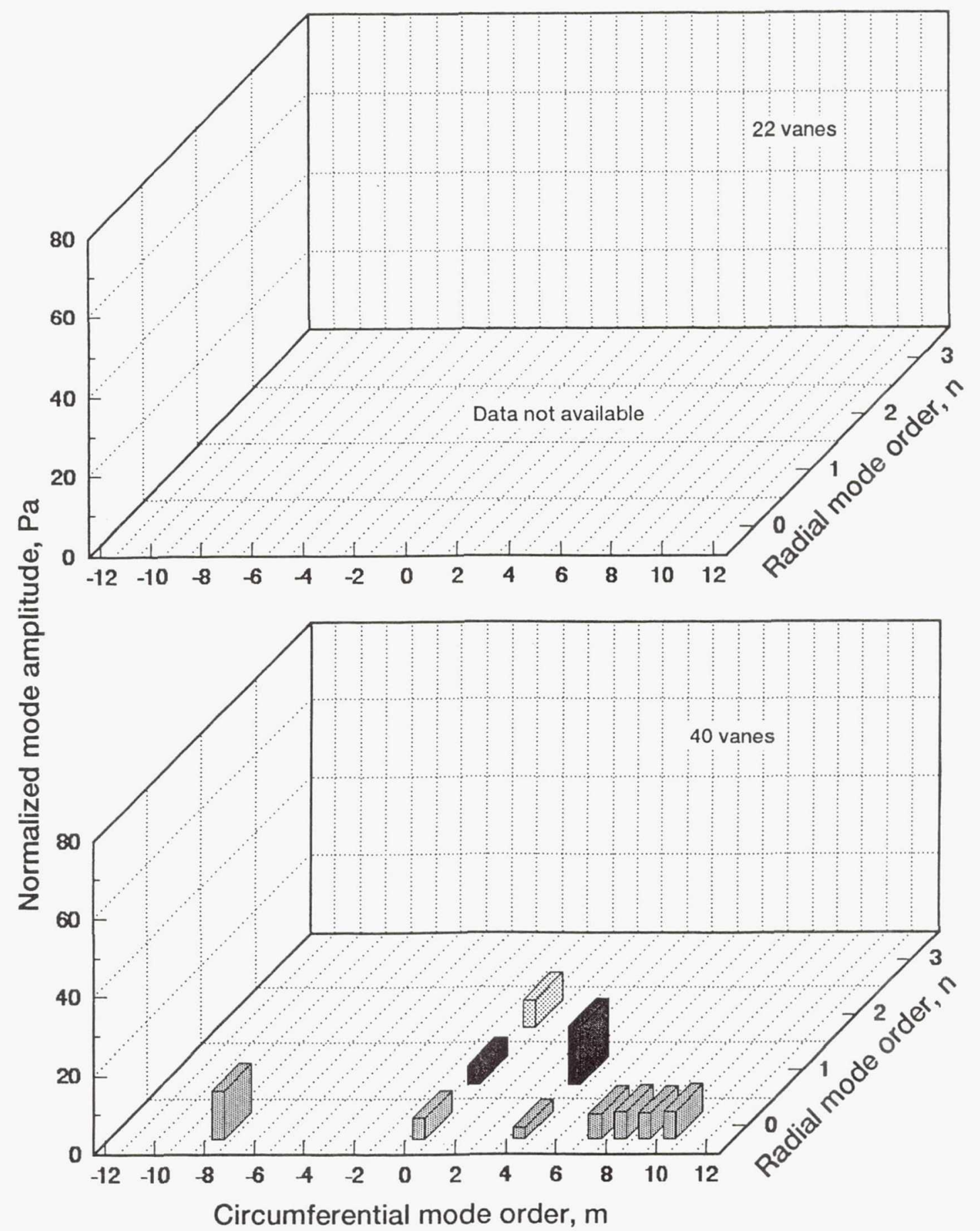

(b) Medium inlet.

Figure 7.-Concluded. 


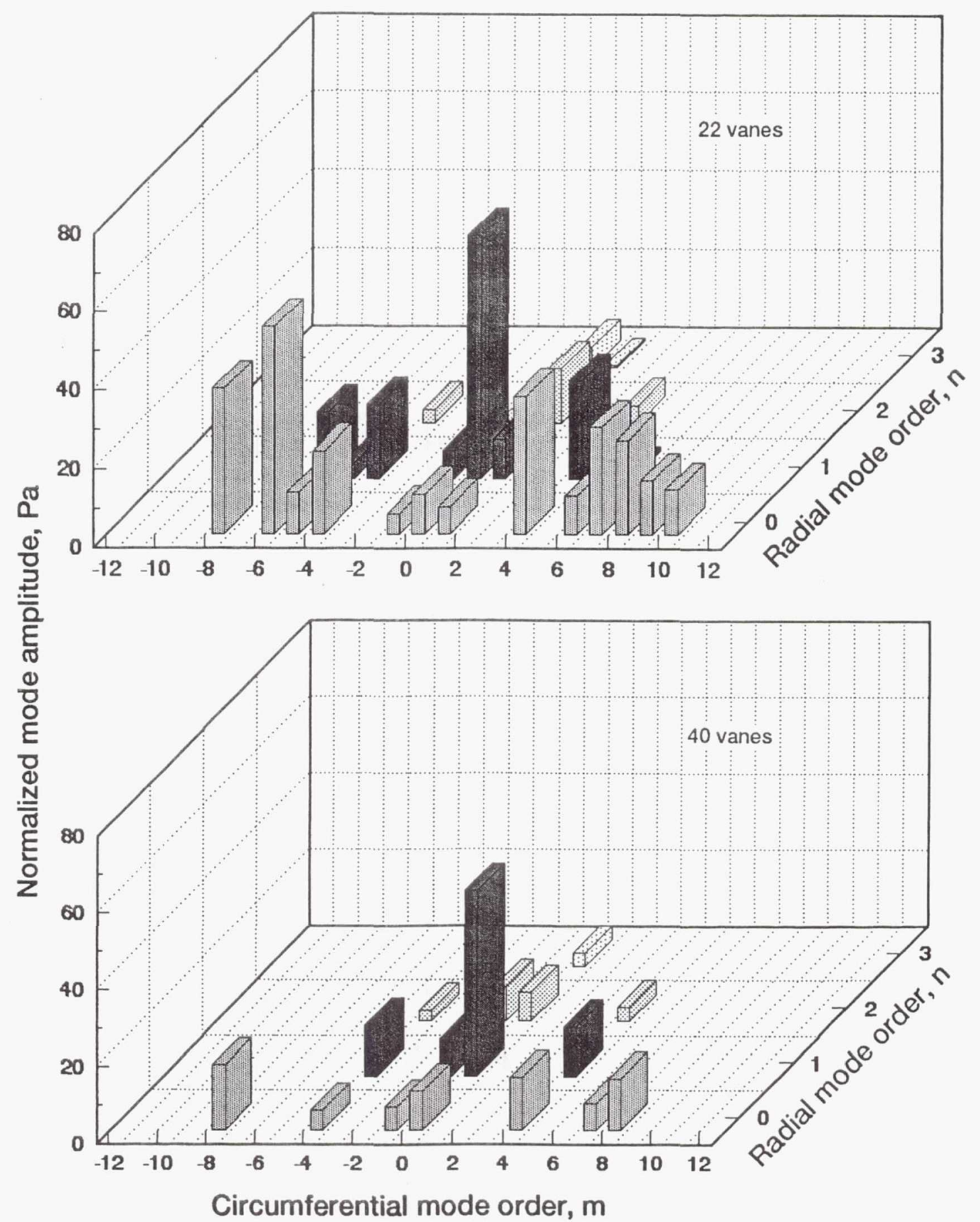

(a) Long inlet.

Figure 8. $-\mathrm{BPF}$ modal structure at $\mathrm{M}_{\mathrm{t}}=0.77$. 


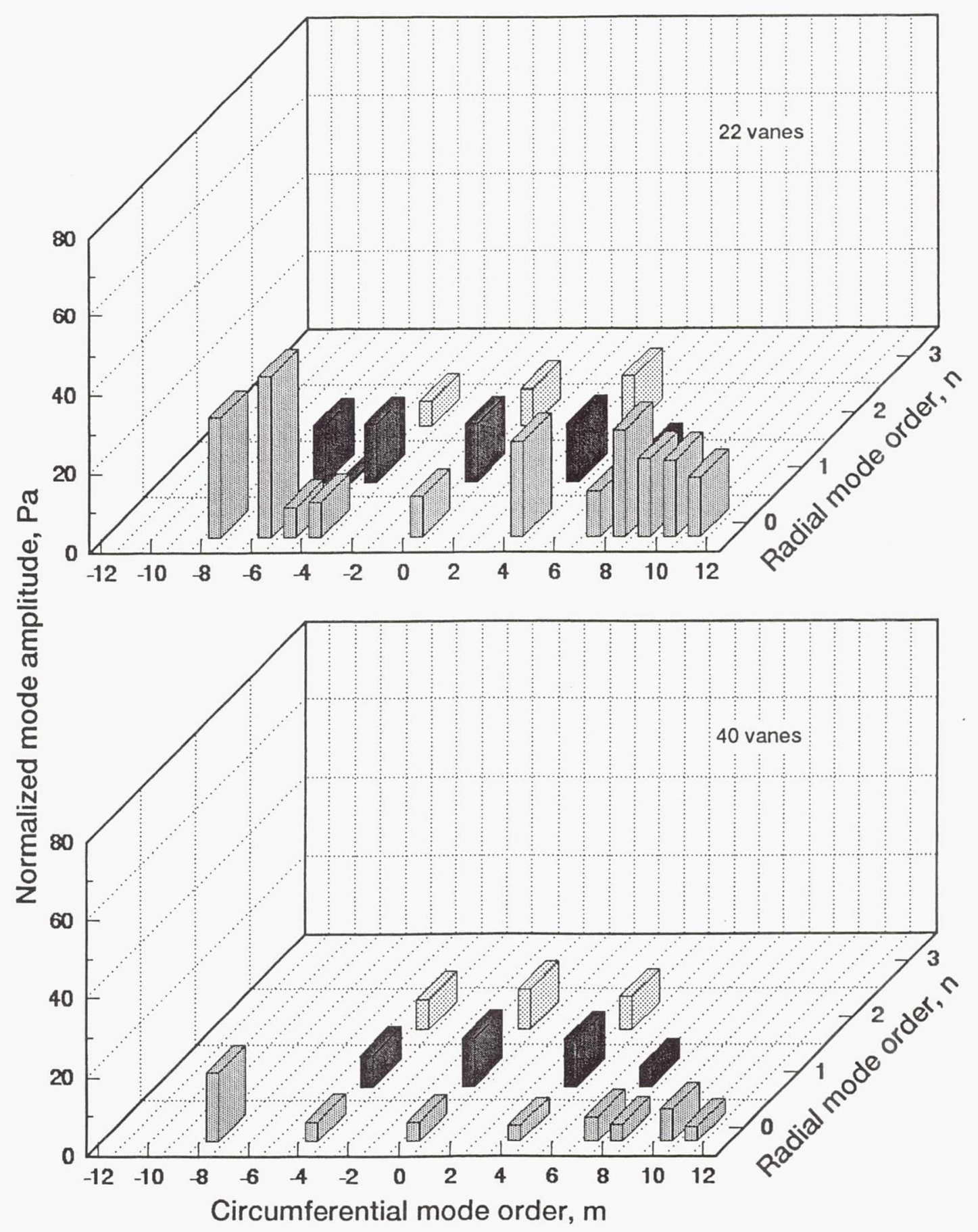

(b) Medium inlet.

Figure 8.-Concluded. 


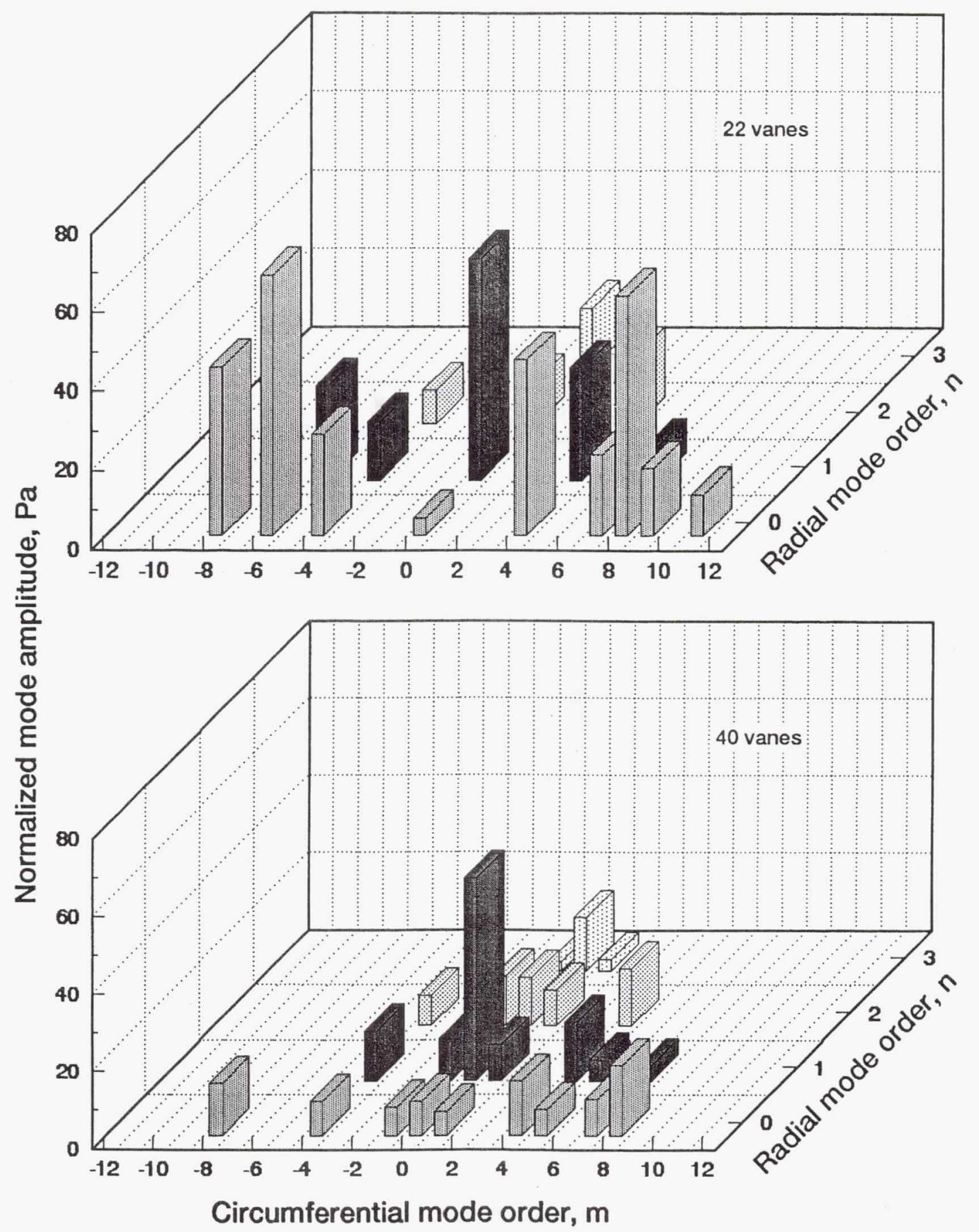

(a) Long inlet.

Figure 9.-BPF modal structure at $\mathrm{M}_{\mathrm{t}}=0.81$. 


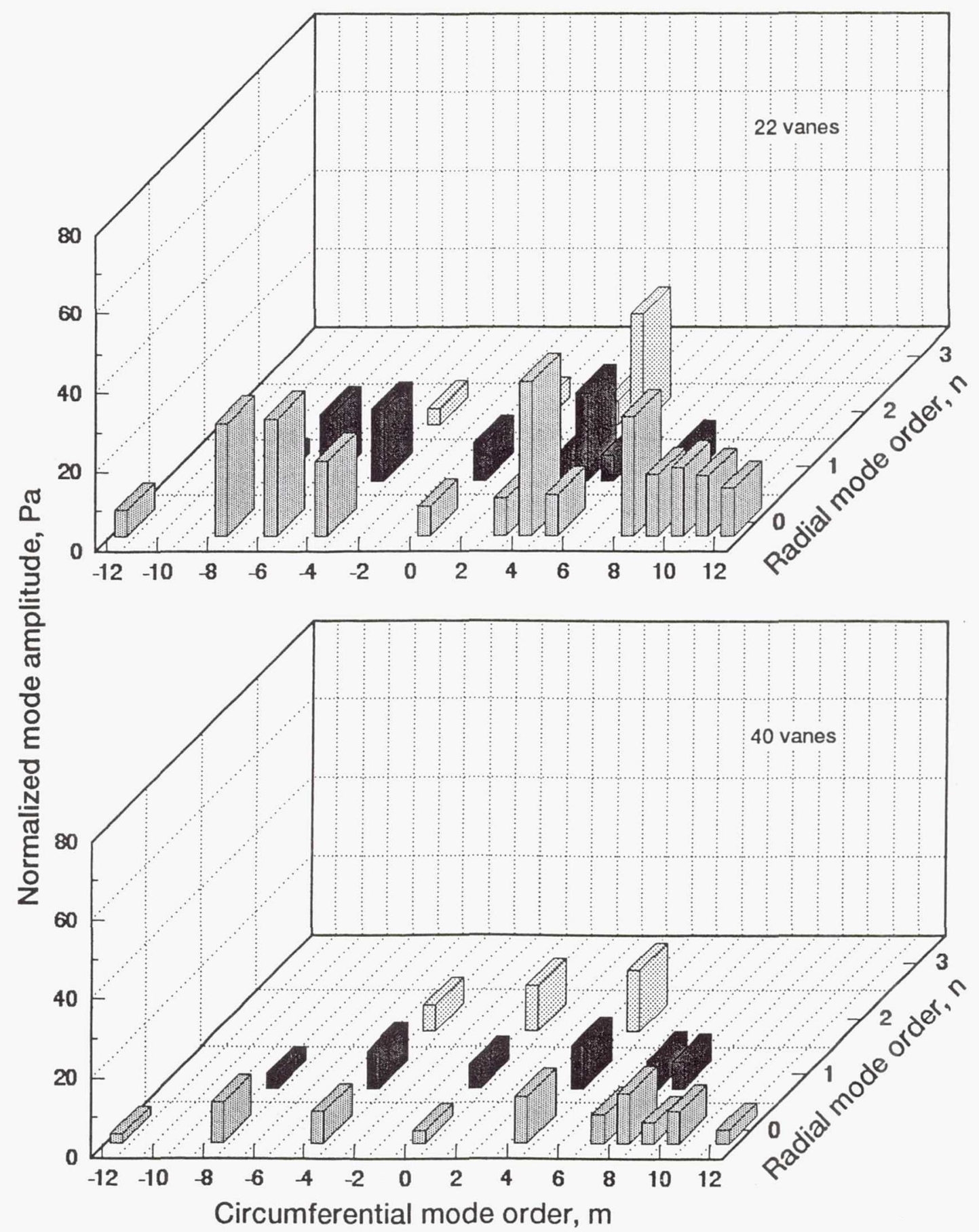

(b) Medium inlet.

Figure 9.-Concluded. 

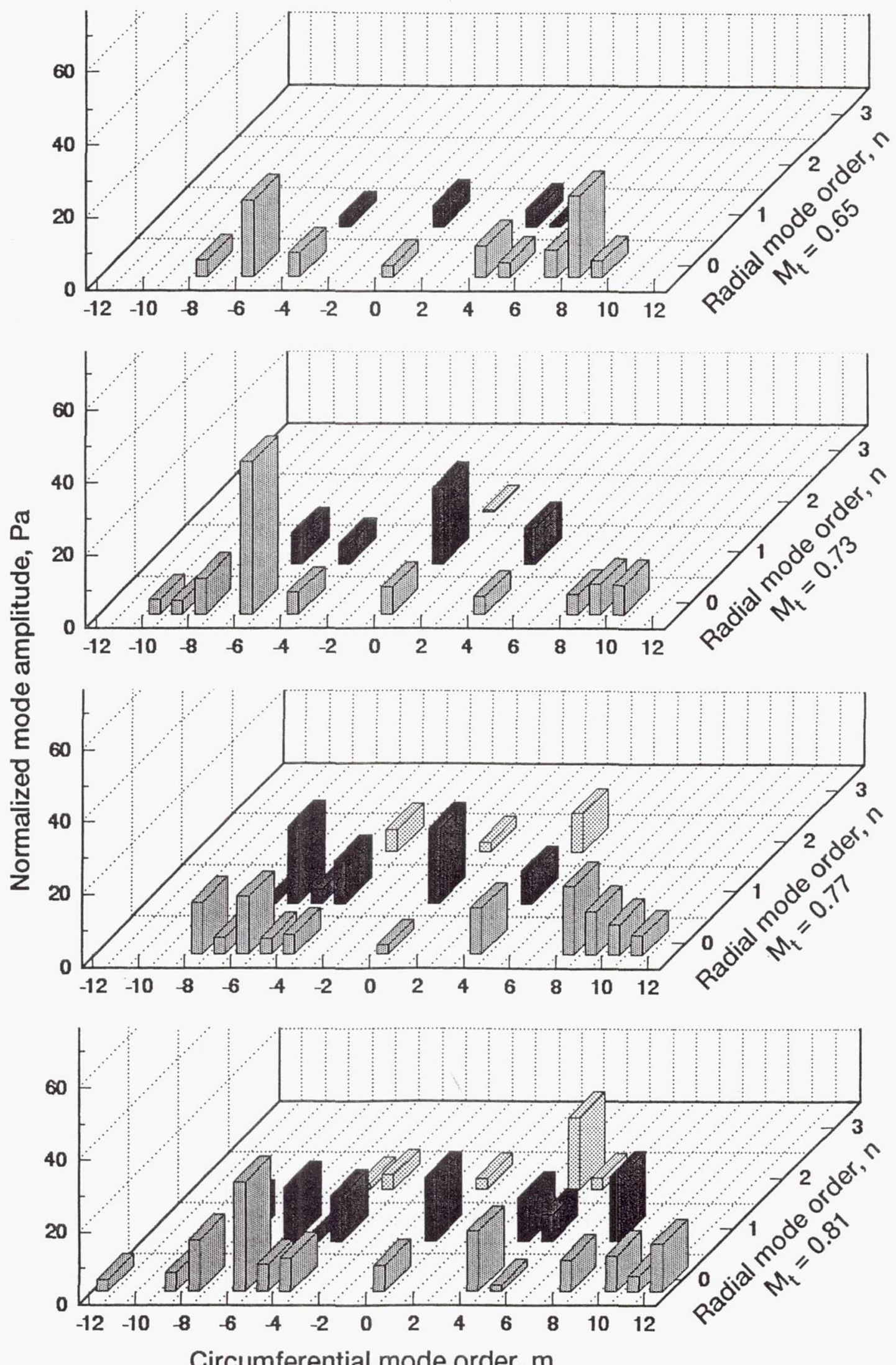

Figure 10.-BPF modal structure for the short inlet with the 22 vane stator. 
Page intentionally left blank 


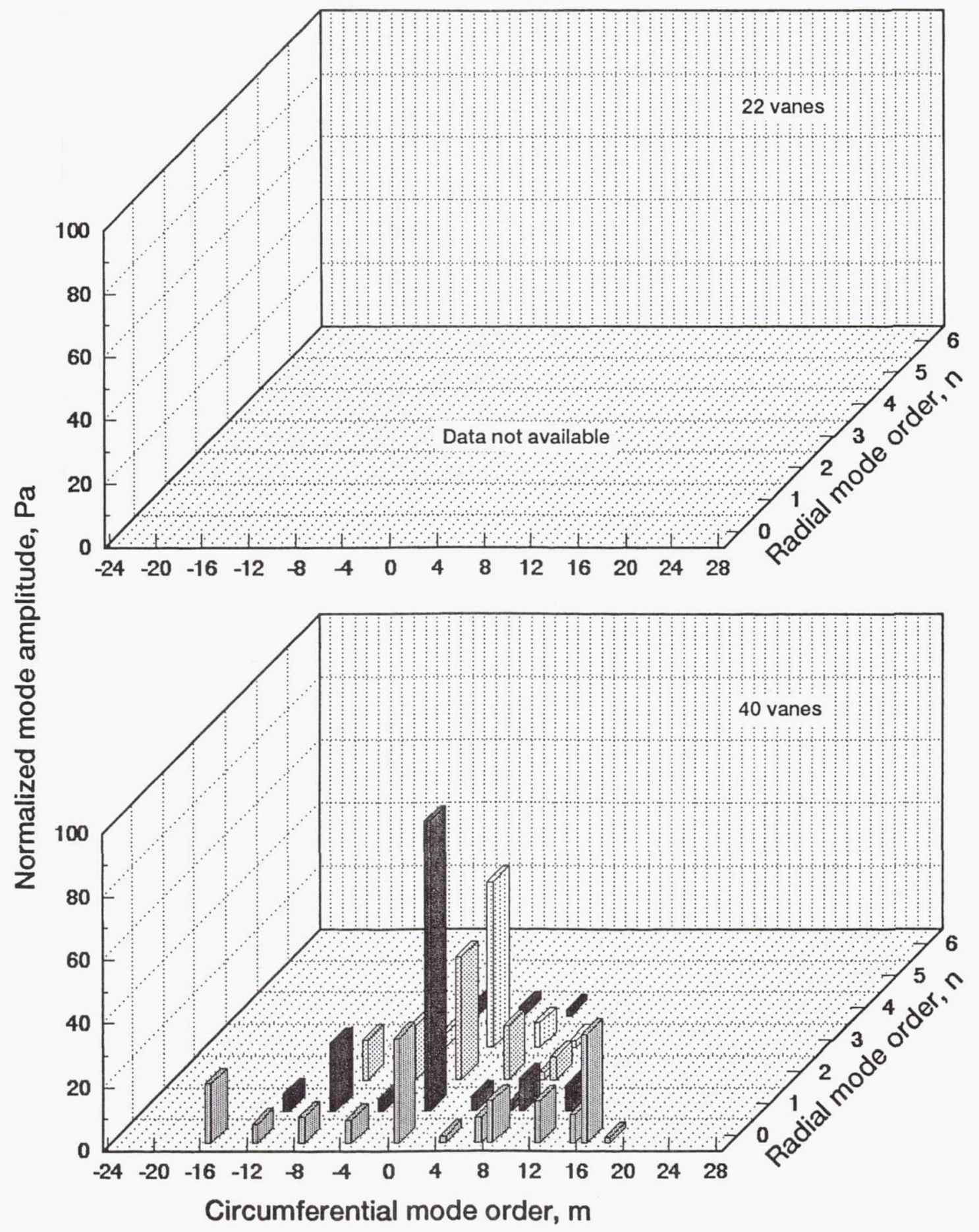

(a) Long inlet.

Figure 11. -2 BPF modal structure at $\mathrm{M}_{\mathrm{t}}=0.65$. 

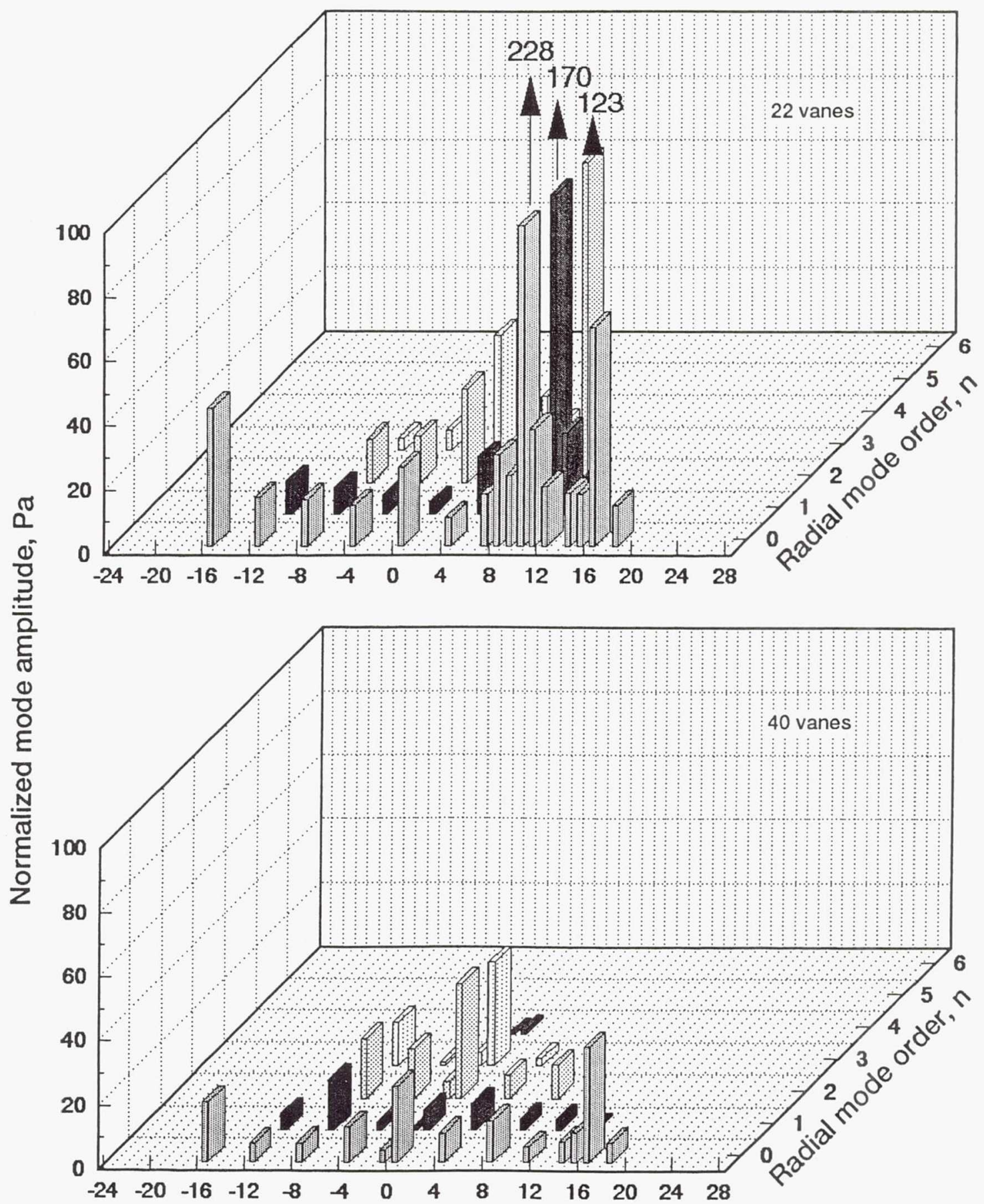

Circumferential mode order, $\mathrm{m}$

(b) Medium inlet.

Figure 11.-Concluded. 


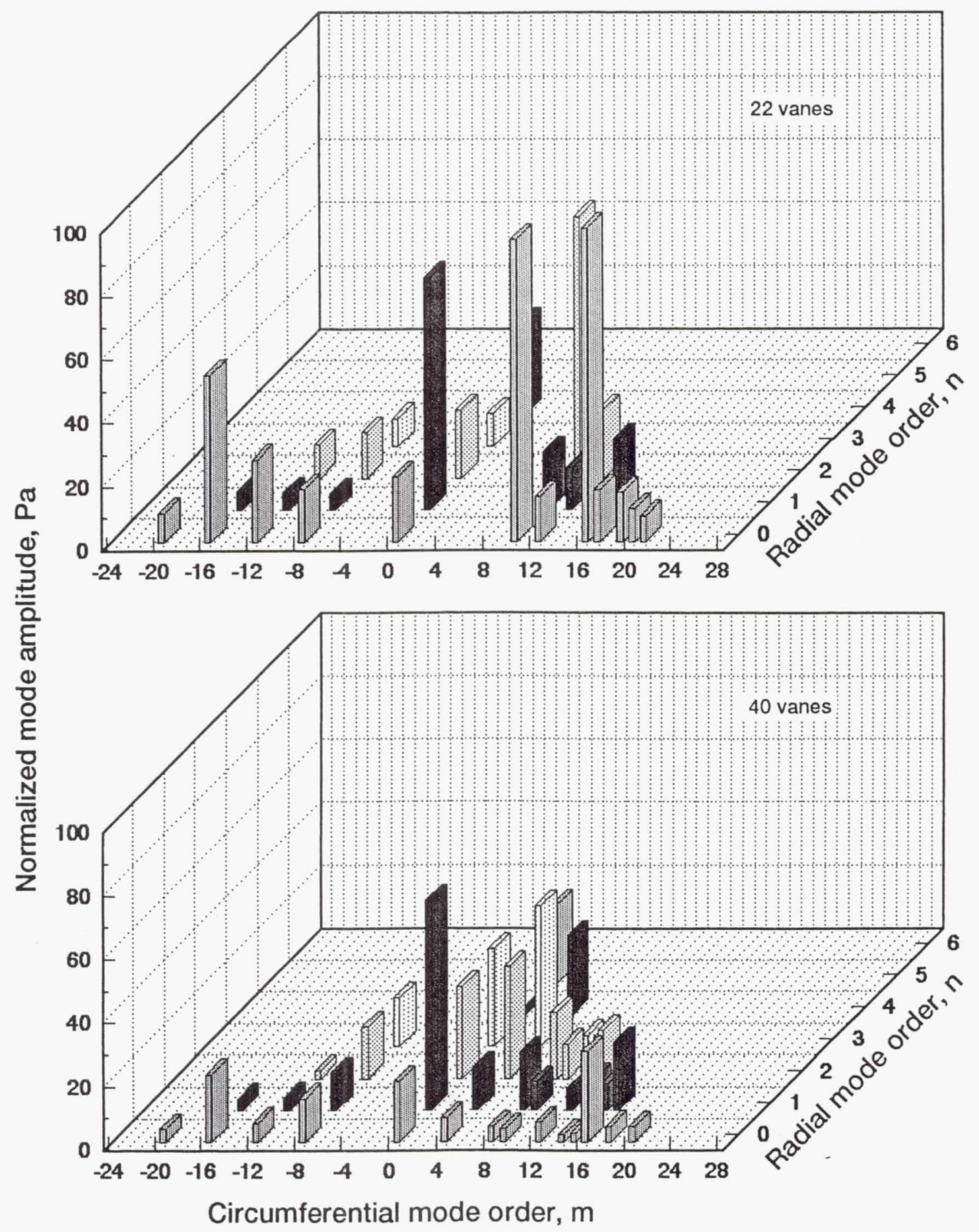

(a) Long inlet.

Figure 12. $-2 \mathrm{BPF}$ modal structure at $\mathrm{M}_{\mathrm{t}}=0.73$. 


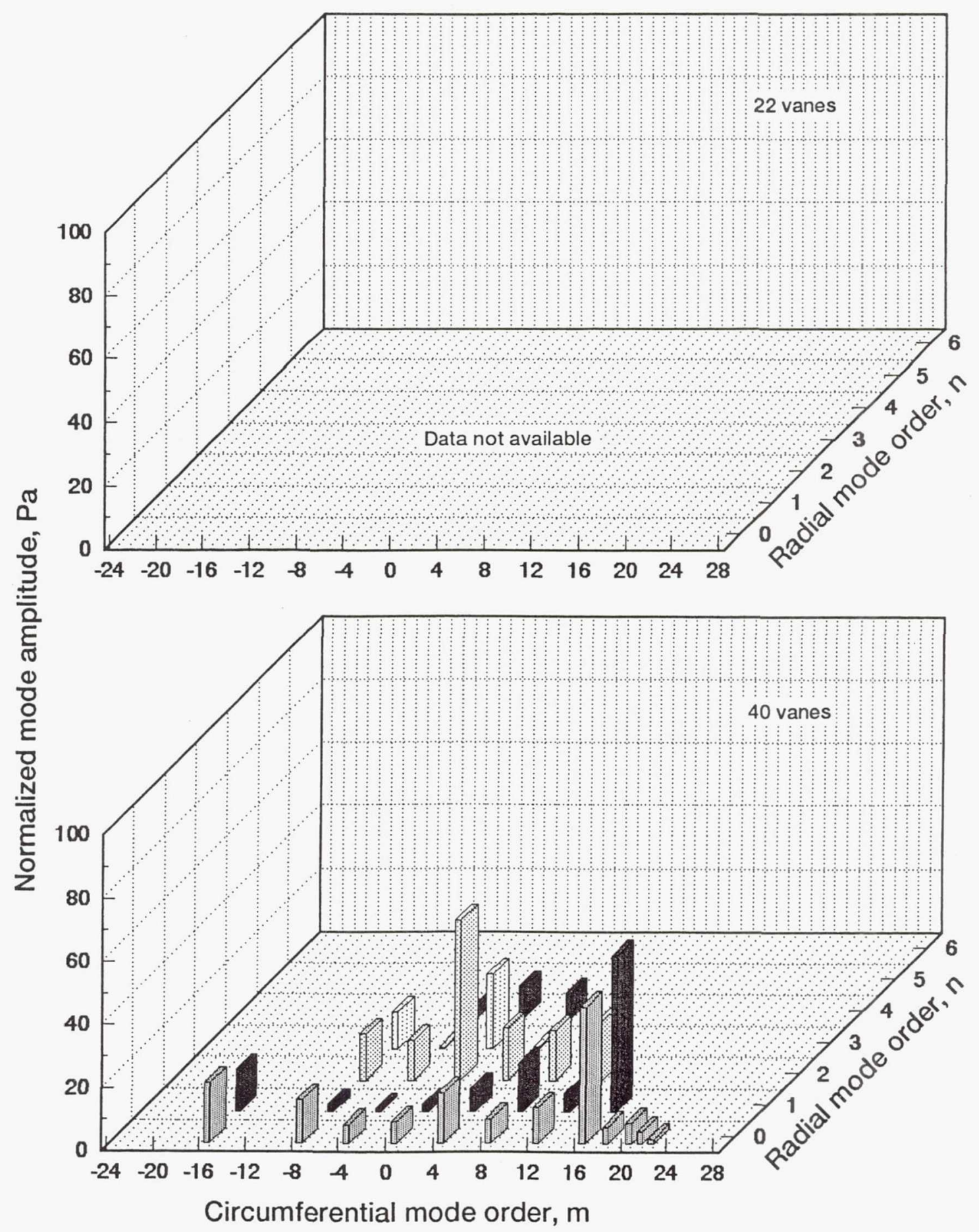

(b) Medium inlet.

Figure 12.-Concluded. 


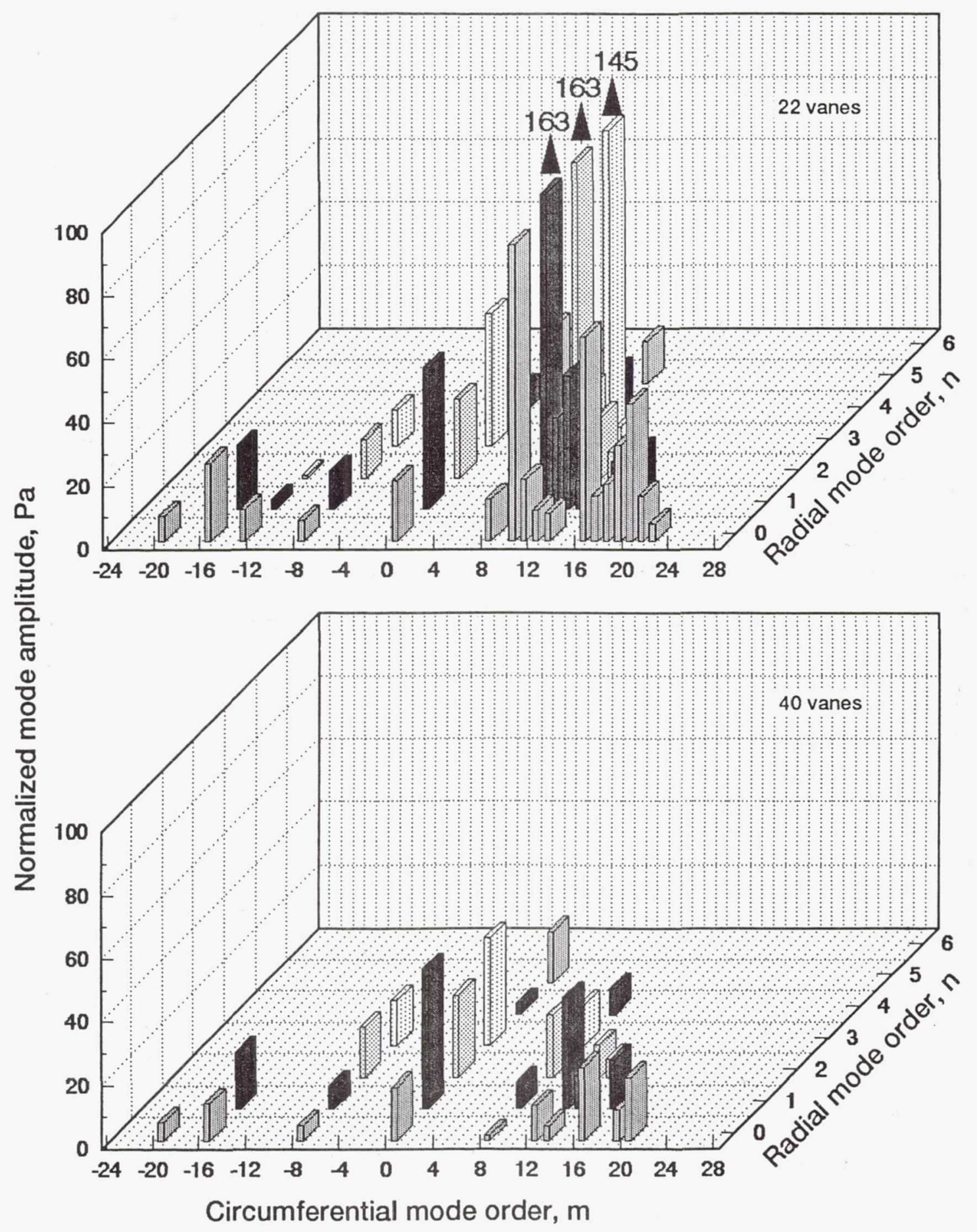

(a) Long inlet.

Figure 13. $-2 \mathrm{BPF}$ modal structure at $\mathrm{M}_{\mathrm{t}}=0.77$. 


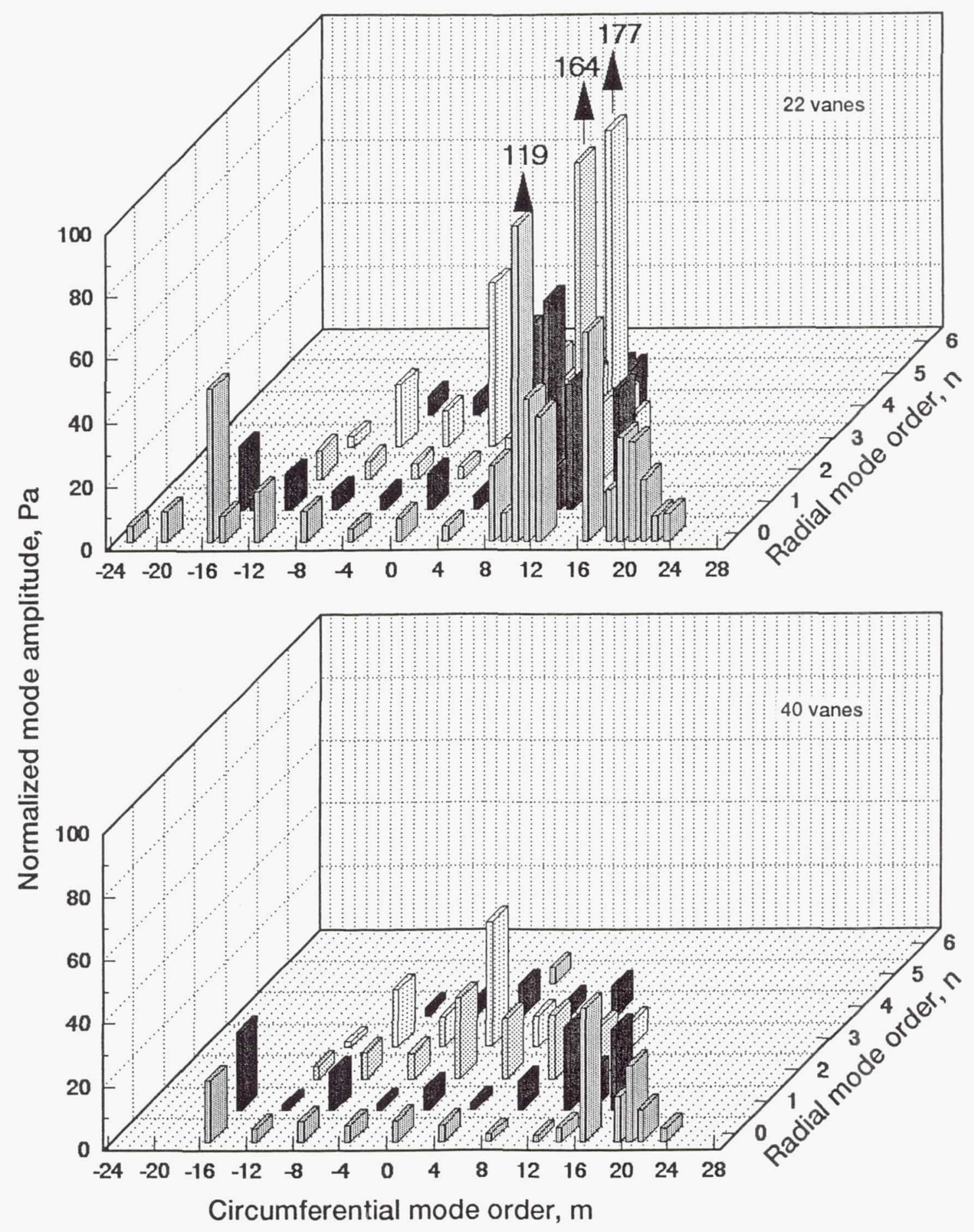

(b) Medium inlet.

Figure 13.-Concluded. 


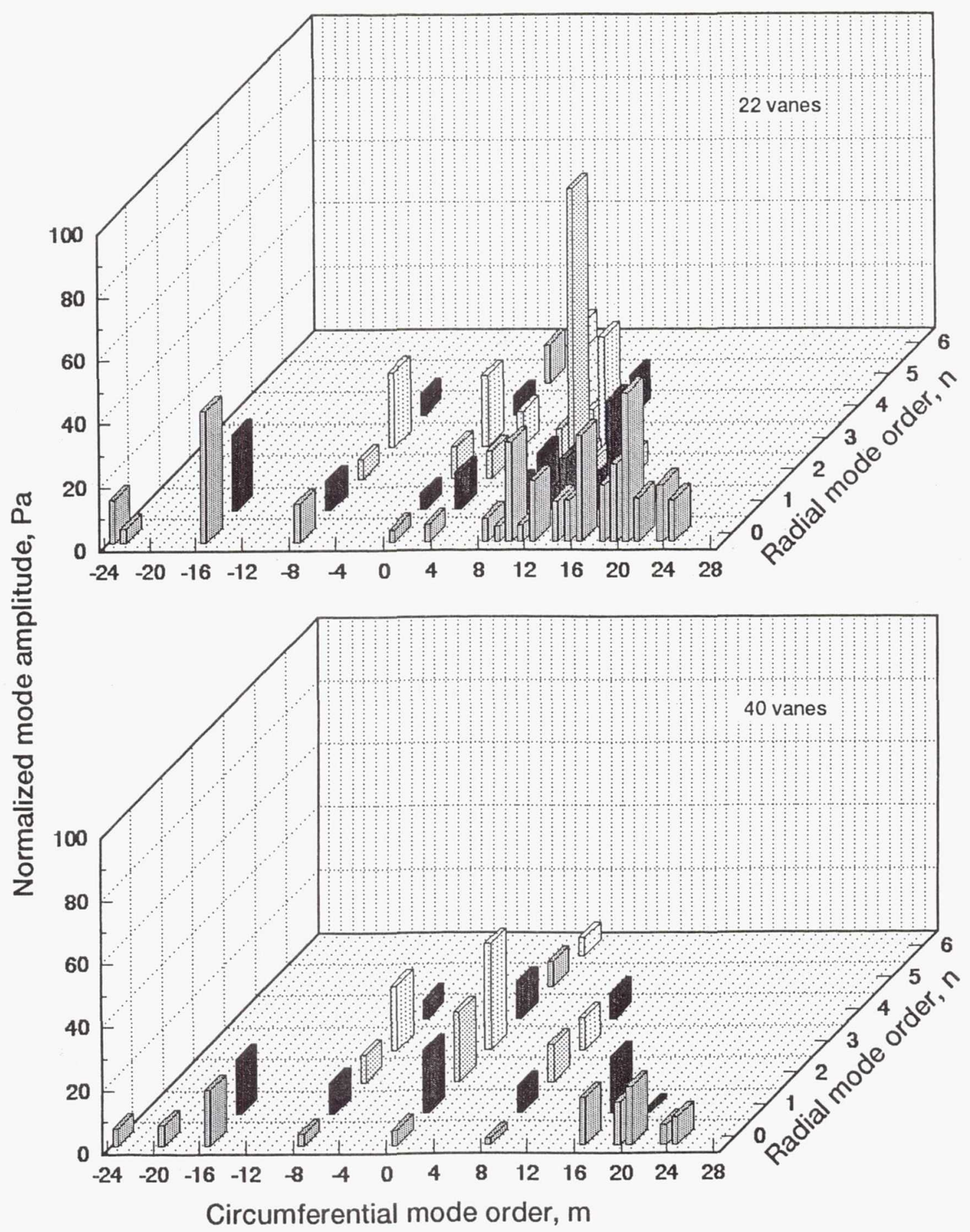

(a) Long inlet.

Figure 14. -2 BPF modal structure at $\mathrm{M}_{\mathrm{t}}=0.81$. 


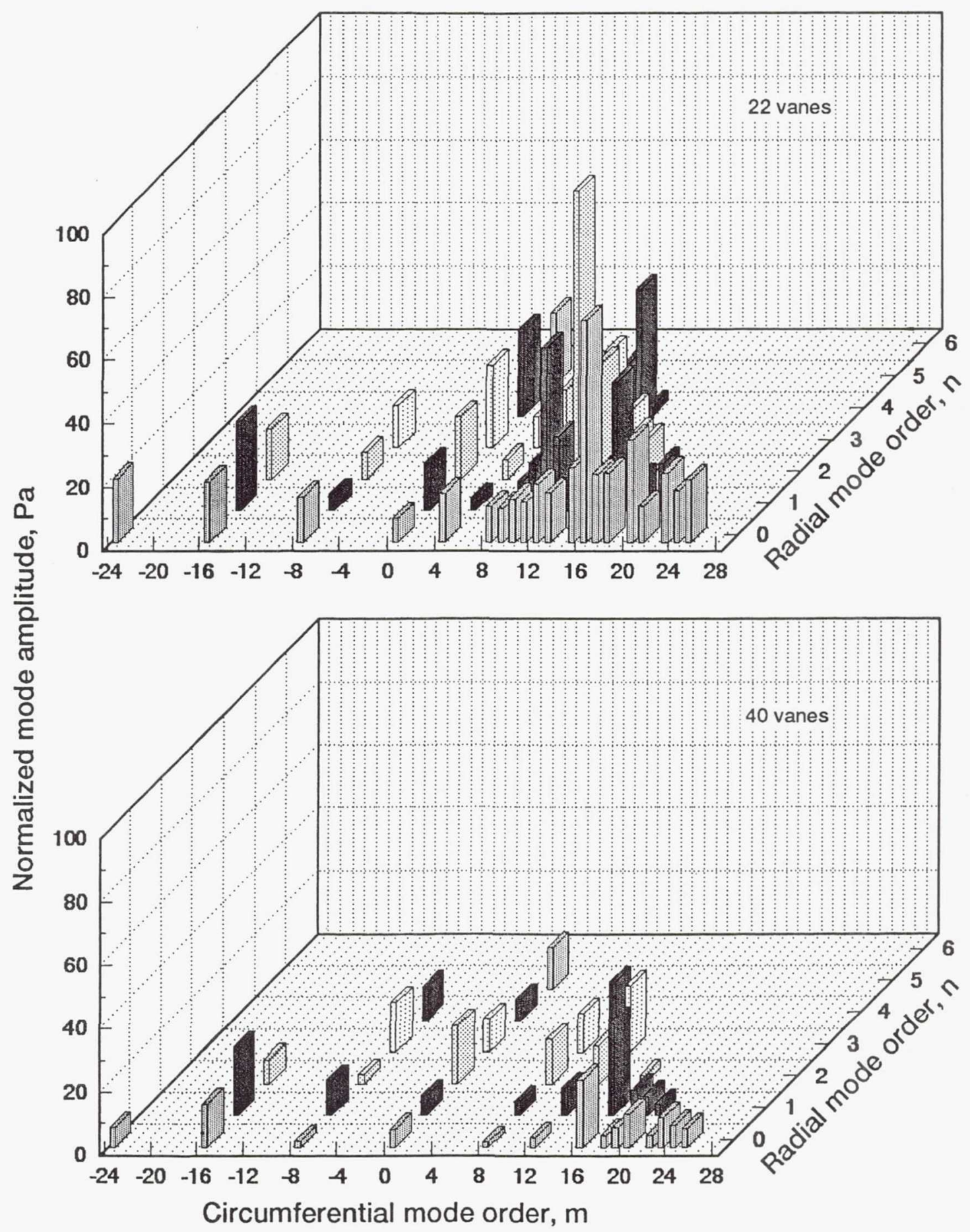

(b) Medium inlet.

Figure 14.-Concluded. 

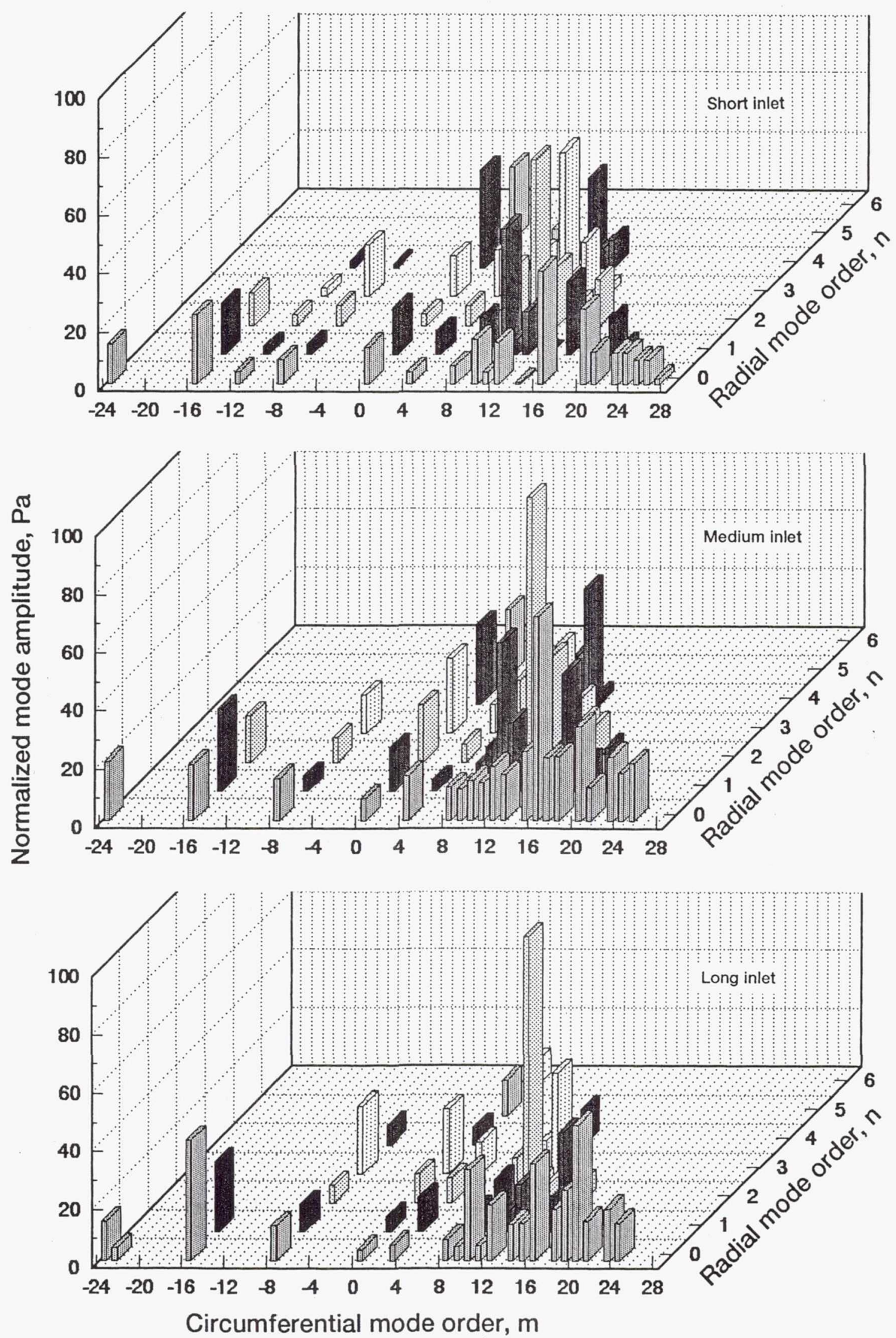

Figure 15.-Comparison of $2 \mathrm{BPF}$ modal structure for all three inlets at $\mathrm{M}_{\mathrm{t}}=0.81$. 
Public reporting burden for this collection of information is estimated to average 1 hour per response, including the time for reviewing instructions, searching existing data sources, gathering and maintaining the data needed, and completing and reviewing the collection of information. Send comments regarding this burden estimate or any other aspect of this collection of information, including suggestions for reducing this burden, to Washington Headquarters Services, Directorate for information Operations and Reports, 1215 Jefferson Davis Highway, Suite 1204, Arlington, VA 22202-4302, and to the Office of Management and Budget, Paperwork Reduction Project (0704-0188), Washington, DC 20503.

\begin{tabular}{|l|l|l|}
\hline 1. AGENCY USE ONLY (Leave blank) & $\begin{array}{c}\text { 2. REPORT DATE } \\
\text { December } 1992\end{array}$ & $\begin{array}{r}\text { 3. REPORT TYPE AND DATES COVERED } \\
\text { Technical Memorandum }\end{array}$ \\
\hline
\end{tabular}

4. TITLE AND SUBTITLE

5. FUNDING NUMBERS

Acoustic Mode Measurements in the Inlet of a Model Turbofan Using a

Continuously Rotating Rake

6. AUTHOR(S)

WU-535-03-10

Laurence J. Heidelberg and David G. Hall

7. PERFORMING ORGANIZATION NAME(S) AND ADDRESS(ES)

National Aeronautics and Space Administration

Lewis Research Center

Cleveland, Ohio 44135-3191

8. PERFORMING ORGANIZATION REPORT NUMBER

9. SPONSORING/MONITORING AGENCY NAMES(S) AND ADDRESS(ES)

10. SPONSORING/MONITORING AGENCY REPORT NUMBER

National Aeronautics and Space Administration

Washington, D.C. 20546-0001

NASA TM-105989

AIAA-93-0598

11. SUPPLEMENTARY NOTES

Prepared for the 31st Aerospace Sciences Meeting sponsored by the American Institute of Aeronautics and Astronautics, Reno, Nevada, January 11-14, 1993. Laurence J. Heidelberg, Lewis Research Center and David G. Hall, Sverdrup Technology, Inc., Lewis Research Center Group, 2001 Aerospace Parkway, Brook Park, Ohio 44142. Responsible person, Laurence J. Heidelberg, (216) 433-3859.

12a. DISTRIBUTION/AVAILABILITY STATEMENT

12b. DISTRIBUTION CODE

Unclassified - Unlimited

Subject Categories 07 and 71

13. ABSTRACT (Maximum 200 words)

Comprehensive measurements of the spinning acoustic mode structure in the inlet of the Advanced Ducted Propeller (ADP) have been completed. These measurements were taken using a unique and previously untried method which was first proposed by T.G. Sofrin. A continuously rotating microphone system was employed. The ADP model was designed and built by Pratt \& Whitney and tested in the NASA Lewis 9- by 15-foot Anechoic Wind Tunnel. Three inlet configurations were tested with cuton and cutoff stator vane sets. The cutoff stator was designed to suppress all modes at the blade passing frequency. Rotating rake measurements indicate that several extraneous circumferential modes were active. The mode orders suggest that their source was an interaction between the rotor and small interruptions in the casing tip treatment. The cuton stator produced the expected circumferential modes plus higher levels of the unexpected modes seen with the cutoff stator.

\section{SUBJECT TERMS}

\begin{tabular}{|c|c|}
\hline & $\begin{array}{c}\text { 15. NUMBER OF PAGES } \\
32\end{array}$ \\
\hline & 16. PRICE CODE \\
\hline $\begin{array}{l}\text { 19. SECURITY CLASSIFICATION } \\
\text { OF ABSTRACT } \\
\text { Unclassified }\end{array}$ & 20. LIMITATION OF ABSTRACT \\
\hline
\end{tabular}


National Aeronautics and

Space Administration

Lewis Research Center

Cleveland, Ohio 44135

Official Business

Penalty for Private Use $\$ 300$
FOURTH CLASS MAIL

ADDRESS CORRECTION REQUESTED
|||||

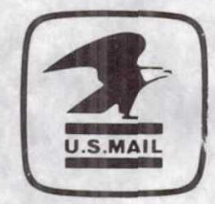

Postage and Fees Paid National Aeronautics and Space Administration NASA 45 